Aus der Abteilung Neurologie

(Prof. Dr. med. M. Bähr)

Im Zentrum Neurologische Medizin

der Medizinischen Fakultät der Universität Göttingen

\title{
Einfluss systemischer Infektionen und ihrer Behandlungen auf den Krankheitsverlauf im Maus-Modell des Morbus Parkinson
}

\author{
INAUGURAL-DISSERTATION \\ zur Erlangung des Doktorgrades \\ der Medizinischen Fakultät der \\ Georg-August-Universität zu Göttingen
}

vorgelegt von

Daniel Gerald Baake

aus Heidelberg

Göttingen 2010 
Dekan:

I. Berichterstatter:

II. Berichterstatter/in:

III. Berichterschtatter/in:
Prof. Dr. med. C. Frömmel

Prof. Dr. med. R. Nau (Betreuer)

Prof. Dr. med. Liebetanz (Korreferent)

Prof. Dr. med. Oppermann (Promotor)

Tag der mündlichen Prüfung: 5.7.2011 


\section{Inhaltsverzeichnis}

1. EINLEITUNG

1.1. NEURODEGENERATIVE ERKRANKUNGEN UND BAKTERIELLE INFEKTIONEN 5

1.2. MORBUS PARKINSON $r$

1.2.1. MAUSMODELL DES MORBUS PARKINSON

$\begin{array}{lr}\text { 1.3. AlPHA-SYNUCLEIN } & 13\end{array}$

1.4. ZIELSETZUNG 16

2. MATERIAL UND METHODEN

$\begin{array}{lr}\text { 2.1. MATERIAL } & 17\end{array}$

2.1.1. GERÄTE 17

2.1.2. VERBRAUCHSMITTEL 18

2.1.3. CHEMIKALIEN UND REAGENZIEN 19

2.1.4. BAKTERIUM 21

2.1.5. ANTIBIOTIKUM 21

2.1.6. ANTIKÖRPER 22

2.1.7. KITS UND ASSAYS 23

2.1.8. PUFFERLÖSUNGEN 23

2.2. METHODEN 24

2.2.1. TIERE 24

2.2.2. INOKULUM 24

2.2.3. INFEKTION 25

2.2.4. TESTVERFAHREN 26

2.2.5. GEWEBEAUFBEREITUNG 29

2.2.6. BCA-PROTEIN-ASSAY 30

2.2.7. ELISA - ENZYME-LINKED IMMUNOSORBENT ASSAY 31

2.2.8. Histologische PROBENAUSWERTUNG 33

2.3. VERSUCHSAUFBAU

2.4. STATISTIK $\quad 41$

3. ERGEBNISSE $\quad 42$

3.1. EINFLUSS REZIDIVIERENDER SYSTEMISCHER INFEKTION MIT SP3 AUF DAS GEWICHT 42

3.2. EINFLUSS REZIDIVIERENDER SYSTEMISCHER INFEKTION MIT SP3 AUF DEN KLINISCHEN

SCORE 44

3.3. EINFLUSS REZIDIVIERENDER SYSTEMISCHER INFEKTION MIT SP3 AUF DEN ROTAROD-TEST 49

3.4. EINFLUSS REZIDIVIERENDER SYSTEMISCHER INFEKTION MIT SP3 AUF DEN SEILTEST $\mathbf{5 1}$

3.5. ÜBERLEBENSZEIT

3.6. HISTOLOGISCHE AUSWERTUNG

3.6.1. HÄMATOXYLIN-EOSIN (HE)- FÄRBUNG 53

3.6.2. ISOLEKTIN-B4 (IB4)- FÄRBUNG

3.6.3. ALPHA-SYNUCLEIN-ÜBBERPRODUKTION

4. DISKUSSION $\quad 55$

5. ZUSAMMENFASSUNG

6. LITERATURVERZEICHNIS $\quad 60$ 
Inhaltsverzeichnis

7. ANHANG

70

7.1. ABKÜRZUNGEN

70

7.2. ABBILDUNGS- UND TABELLENVERZEICHNIS

74

7.2.1. ABBILDUNGSVERZEICHNIS

74

7.2.2. TABELLENVERZEICHNIS

74 


\section{Einleitung}

\subsection{Neurodegenerative Erkrankungen und bakterielle Infektionen}

Als neurodegenerative Erkrankungen bezeichnet man eine Gruppe von Erkrankungen des Nervensystems, die meist langsam fortschreiten und erblich oder sporadisch auftreten. Die Pathogenese dieser Erkrankungen ist zum größten Teil noch unbekannt.

Hauptmerkmal aller neurodegenerativen Erkrankungen ist der fortschreitende Verlust von Nervenzellen, der zu verschiedenen neurologischen Symptomen darunter häufig zu Demenz und Bewegungsstörungen - führt. Die Erkrankungen können in unterschiedlichen Lebensaltern auftreten, verlaufen diffus oder generalisiert und rufen charakteristische histologische Schädigungsmuster hervor.

Inflammatorische Prozesse stehen in dem Verdacht, neurodegenerative Erkrankungen wie Multiple Sklerose (MS), Amyotrophe Lateralsklerose (ALS) oder auch Morbus Parkinson (PD) in ihrem Auftreten zu beschleunigen, zu verschlimmern oder ihr Auftreten zu einem früheren Zeitpunkt zu induzieren. Diese verbreitete klinische Annahme ist bis jetzt nur in wenigen, meistens auf den Morbus Alzheimer (AD) gerichteten Studien untersucht (Holmes et al. 2003). Systemische Infektionen, z.B. Harnwegsinfekte, können bei Patienten mit neurodegenerativen Erkrankungen häufiger auftreten und bei Demenzerkrankten bis zum Auftreten eines Delirs führen, was wiederum zu einem rascheren Verlust an kognitiven Funktionen führt (Murray et al. 1993; Elie et al. 1998; Albert et al. 1999; Gelanis 2001; Holmes et al. 2003). Vor diesem Hintergrund muss der modulierende Effekt einer systemischen Infektion auf den Verlauf von neurodegenerativen Erkrankungen diskutiert und weiter erforscht werden.

Der bei der Verschlimmerung neurodegenerativer Erkrankungen durch Infektionen zugrunde liegende Pathomechanismus ist bis heute noch nicht vollständig geklärt. Angenommen wird, dass Toll-like-Rezeptor-Agonisten (TLR-A) wie LPS oder CPG, beides Bakterienbestandteile, zu einer verstärkten 
Aktivierung der bereits prä-aktivierten Mikrogliazellen führen (Lemstra et al. 2007).

Aktivierte Mikrogliazellen gelten als Hauptbestandteile der körpereigenen Immunabwehr im zentralen Nervensystem (ZNS) (Aloisi 2001) und wurden im Gehirn bei Patienten mit AD (van Evenbroeck et al. 2004; Kim et al. 2002), PD (McGeer und McGeer 2004; McGeer et al. 1988) und ALS (Turner et al. 2004) gefunden.

Aktivierte Mikrogliazellen stimulieren als Folge die inflammatorische Zytokinsynthese innerhalb des ZNS (Pitossi et al. 1997; Laye et al. 1994; Barrientos et al. 2006) und sind als körpereigene Immunantwort in der Lage, die Neuronen im ZNS zu schützen, bei zu starker Aktivierung aber auch zu schädigen (Ilev et al. 2004; Kreutzberg 1996; Nguyen et al. 2002; Wyss-Coray und Mucke 2002).

Die Aktivierung der Mikrogliazellen durch Bakterien (Ebert et al. 2005) und endogene Proteine wie B-Amyloid $(A B)$ oder $\alpha$-Synuclein (Lotz et al. 2005; Zhang et al. 2005) könnte eine wichtige Querverbindung zwischen systemischen Infektionen und neurodegenerativen Erkrankungen darstellen. $\alpha-$ Synuclein konnte jüngst in nativem CSF quantifiziert und konnte bei verschiedensten Krankheiten des ZNS, wie z.B. PD, CJD, Paraneoplasie und akutem Kopfschmerz, nachgewiesen werden (Mollenhauer et al. 2008).

Eine systemische Infektion durch Endotoxine (LPS) in Mäusen mit Prionenerkrankungen führte zu einer Häufung der inflammatorischen Prozesse im Gehirn, zu einer Zunahme der Neurodegeneration und zu einer Verschlechterung der motorischen Leistung (Cunningham et al. 2005; Combrinck et al. 2002; Cunningham et al. 2009). Mollenhauer gelang 2008 erstmalig der quantifizierte Nachweis einer statistisch signifikanten Erhöhung von $\alpha$-Synuclein aus Liquor bei an der Creutzfeld-Jakob-Krankheit leidenden Menschen sowohl in vivo als auch post mortem durch Autopsie (Mollenhauer et al. 2008). 
In einer weiteren Untersuchung konnte gezeigt werden, dass eine wiederholte intraperitoneale Injektion von LPS zu einer Exazerbation der experimentellen ALS und einer Degeneration der motorischen Axone führt (Nguyen et al. 2004).

In einem weiteren Mausmodell, dem Tiermodell der MS, wurde gezeigt, dass die experimentelle autoimmune Enzephalitis (EAE) durch eine systemische Infektion mit Streptococcus pneumoniae (S. pneumoniae) verschlimmert wurde (Hermann et al. 2006). 


\subsection{Morbus Parkinson}

Die parkinsonsche Erkrankung wurde erstmals unter dem Titel „An Essay on the Shaking Palsy" von James Parkinson, einem Londoner Arzt, in seiner Monographie im Jahre 1817 beschrieben. Hiervon leitet sich der lateinische Name Paralysis agitans ab, der von M. Hall 1841 eingeführt und im Volksmund unter dem Begriff der „Schüttellähmung“ populär wurde.

Die für das idiopathische Parkinsonsyndrom typische Symptomkonstellation mit Rigor, Tremor und Bradykinese ist 1000-1500 vor Christus in ayurvedischen Schriften erstmalig festgehalten worden (Manyam 1990).

Neben der Alzheimer-Demenz gilt der Morbus Parkinson als zweithäufigste neurodegenerative Zerebralerkrankung, unter der in den Ländern der Europäischen Union etwa eine halbe Millionen Menschen leiden. Die Prävalenz variiert zwischen 60-200/100.000 Einwohner und nimmt mit dem Alter zu. Die Erkrankung ist bei Männern häufiger auf als bei Frauen, bei den über 60Jährigen liegt sie bei $1 \%$, bei über 80 -Jährigen nähert sie sich bereits $3 \%$ (Dluzen und McDermott 2000). Somit gilt das Alter als einer der Hauptrisikofaktoren für den Morbus Parkinson. Wenn auch bei den meisten Patienten die Entstehungsursache unbekannt bleibt, so wird bei $5-10 \%$ eine genetische Grundlage gefunden (Wood-Kaczmar et al. 2006). Das idiopathische Parkinsonsyndrom (PD) muss hierbei vom Parkinsonismus unterschieden werden, das etwa zehn mal häufiger vorkommt (Berlit 2005).

Die Erkrankung ist in verschiedene Formen unterteilt: die primäre idiopathische Form, die mit 80 - $90 \%$ aller Parkinsonformen am häufigsten auftritt, die hereditäre Form und das Parkinson-Syndrom (z.B. nach Infektion).

Den o.g. Formen gemeinsam ist eine Reduktion der Neurone in der Substantia nigra, die zu einer dopaminergen Minderinnervation des Striatums führt. Eine Ausnahme stellt das neuroleptisch-induzierte Parkinson-Syndrom dar. Ab einem Verlust von ca. $60 \%$ der Neurone oder einer Dopaminreduktion von ca. $80 \%$ im Striatum kommt es zu den Kardinalsymptomen des Morbus Parkinson: Tremor, Rigor und Bradykinese (McGeer et al. 1988; Fearnley und Lees 1991; 
Bernheimer et al. 1973). Somit kann man von einer ca. 5 Jahre langen präsymptomatischen Phase der Erkrankung ausgehen (Fearnley und Lees 1991).

Die Ätiologie und Pathogenese des Morbus Parkinson sind bis heute noch nicht komplett entschlüsselt. Bisher bekannt ist, dass eine charakteristische Degeneration der dopaminergen Neuronen der Zona compacta der Substantia Nigra (SNC) vorliegt, was zu einem Defekt im zerebralen neuronalen System führt.

Beim idiopathischen Parkinson-Syndrom sind vor allem die venterolateralen Anteile, die zum Putamen ziehen, betroffen. Dieser Schaden kann durch das Auftreten von Lewy Bodies als Einschlusskörperchen in den dopaminergen Neuronen der Substantia nigra nachgewiesen werden (Lewy 1912; Forno et al. 1995).

Lewy Bodies (LB) wurden erstmals 1912 von dem Neurologen Frederic Lewy mit Morbus Parkinson in Verbindung gebracht. Sie sind charakteristische Strukturen, die post mortem bei Patienten mit Morbus Parkinson gefunden werden. Es handelt sich hierbei um runde zytoplasmatische Einschlusskörperchen der Neuronen im Gehirn. Sie besitzen normalerweise einen dichten, eosinophilen Kern mit blassem Halo (Duffy und Menefee 1965) und bestehen aus $\alpha$-Synuclein (AS), Ubiquitin, Neurofilamenten und anderen Proteinablagerungen.

Es wurde gezeigt, dass das präsynaptische Protein AS in der Pathogenese des Morbus Parkinson eine wesentliche Rolle spielt (Spillantini et al. 1997; Spillantini et al. 1998). LB kommen jedoch auch bei anderen neurodegenerativen Erkrankungen, z.B. dem Morbus Alzheimer, vor (Lang und Lozano 1998). Bei zwei Formen der Parkinsonerkrankung, der infektiösen Encephalitis lethargica und dem familiär-juvenilen autosomal-rezessiv vererbten Parkinson-Syndrom, zeigen sich keine Einschlusskörperchen.

Eine exogene toxische Ursache des PD wurde angenommen, nachdem Drogenabhängige durch die Injektion von mit 1-Methyl-4-Phenyl-1,2,3,6- 
Tetrahydro-Pyridin (MPTP) verunreinigten Meperidin-Analoga ein ParkinsonSyndrom entwickelten (Langston et al. 1983). MPTP wird in Gliazellen über die Monoaminooxidase B in das L-Methyl-Phenyl-Pyridinium-Ion (MPP+) oxidiert und über den Dopamintransporter selektiv in dopaminerge Neuronen aufgenommen (Javitch et al. 1985). MPP+ inhibiert effektiv den Komplex I der mitochondrialen Atmungskette (Nicklas 1984; Ramsay et al. 1986). Es konnte so eine verminderte Aktivität der mitochondrialen NADH-Dehydrogenase in der SNC nachgewiesen werden, was insgesamt zur verminderten Energiebereitstellung für Stoffwechselprozesse im Gehirn führt (Dexter et al. 1990; Jellinger et al. 1993; Sian et al. 1994). Somit führt ein Ausfall des dopaminergen Systems zum Wegfall der Hemmung anderer Bestandteile des Schaltkreises und damit zu den Symptomen des Morbus Parkinson (Trepel 2008).

Auf Grund der bisher unbekannten Ursache/Ursachen für die Erkrankung des IPS steht bis zum heutigen Tage keine kausale Therapie zur Verfügung. Therapeutische Ansätze sind derzeit die medikamentöse Therapie oder alternativ dazu die symptomatisch operative Therapie: Medikamentöse Ansätze erfolgen durch Dopaminbereitstellung (Levodopa), Inhibitoren des Dopaminabbaus/-metabolismus (COMT-MAO-B-Hemmer) und DopaminRezeptor-Agonisten (Bromocriptin, Lisurid, Ropinirol). Acetylcholin-RezeptorAntagonisten (z.B. Trihexyphenidyl, Biperiden) waren neben Glutamatrezeptorantagonisten (Amantadin) und atypischen Parkinsonmitteln wie Budipin mit die ersten Medikamente im Bereich der medikamentösen Therapie, verlieren jedoch zunehmend an Bedeutung im klinischen Alltag. Operativ kann durch Thermokoagulation, hochfrequente Tiefenhirnstimulation und Transplantation von z.B. fetalen Hirnzellen ein Therapieversuch unternommen werden.

Neue Therapieansätze in der neuroprotektiven/neuroregenerativen Therapie durch Beeinflussung des oxidativen Stresses, der Exitotoxizität, der mitochondrialen Dysfunktionen, der immunologischen Faktoren, der Applikation 
neurotropher Faktoren sowie der Ubiquitin/Proteasomen-Funktionsstörung werden erprobt.

Es ist weiterhin ungeklärt, ob die oben genannten Prozesse primär oder nur sekundär mit dem Krankheitsgeschehen in Zusammenhang stehen. Nichtsdestotrotz werden gerade diese Therapieansätze rege erforscht.

\subsubsection{Mausmodell des Morbus Parkinson}

Es existiert eine Reihe von Modellen, die zur Untersuchung des Morbus Parkinson herangezogen werden können. Eines dieser Modelle, das Intoxikationsmodell, wird primär zur Untersuchung des motorischen Verlustes verwendet. Als Tiere werden hier vor allem Drosophilafliegen gewählt, die als Neurotoxin 1-Methyl-4-Phenyl-1,2,3,6-Tetrahydropyridin (MPTP) exprimieren. Dieses Neurotoxin induziert einen signifikanten dopaminergen Neuronenschaden (Dawson et al. 2002).

Um die Schlüsselsymptome des Morbus Parkinson besser kopieren zu können, wurden andere Modelle entwickelt, die auf dem genetischen und neuropathologischen Zusammenspiel von $\alpha$-Synuclein und Morbus Parkinson basieren (Betabert et al. 2002; Beal 2001; Dawson et al. 2002). Daraus wurde das in dieser Arbeit verwendete Tiermodell entwickelt: es wurden transgene Mäuse mit der Mutation (THY1)-A30PaSYN als Versuchstiere genutzt. Diese Mutanten exprimieren das humane $\alpha$-Synuclein-Gen mit der A30P Mutation, die bei der early-onset-Form des PD unter der THY1-Kassette gefunden wird (Kahle et al. 2001).

Die Exprimierung des mutanten $\alpha$-Synucleins, das den Promotor THY1 verwendet, führt zu einem signifikanten Defekt der neuromuskulären Endplatte (neuromuscular junctions) und damit zur axonalen Degeneration (van der Putten et al. 2000). Die hier verwendeten Tiere entwickelten im Alter zwischen 6 und 14 Monaten erstmalig klinische Symptome des IPS. Beginnend mit einem Tremor kamen unter fortschreitender Krankheitsdauer die muskuläre Instabilität 
Einleitung - Morbus Parkinson

bis hin zur das Endstadium charakterisierenden Paralyse als Symptome hinzu (Kahle et al. 2000; Frasier et al. 2005). 


\subsection{Alpha-Synuclein}

Alpha-Synuclein ist als häufiges präsynaptisches Protein, das bevorzugt im Endhirn exprimiert wird, für den Aufbau der Membranstabilität zuständig und an neuronalen Veränderungen beteiligt und macht ca. 1\% des gesamten löslichen Gehirnproteins aus (Recchia et al. 2004; Iwai et al. 1995). In der Präsynapse liegt neben $\alpha$-Synuclein auch $\beta$-Synuclein in hauptsächlich zytosolischer Form vor (Kahle et al. 2000; Clayton und George 1999; Iwai et al. 1995; Nakajo et al. 1994; Shibayama-Imazu et al. 1993). In vitro bindet $\alpha$-Synuclein an Vesikel, die einen hohen Anteil saurer Phospholipide enthalten (Davidson et al. 1998). Durch die Bindung verändert das Protein seine Struktur von ungefaltet in eine $\alpha$-helikale Struktur, wobei insbesondere der $\mathrm{N}$-Terminus beteiligt ist (Davidson et al. 1998; Clayton und George 1998; Weinreb et al. 1996).

Über die physiologische Funktion von Synuclein ist trotz intensiver Forschung bisher nur wenig bekannt. Neben dem indirekten Hinweis auf eine Beteiligung bei der synaptischen Plastizität wurde eine Funktion in der Signaltransduktion vermutet. In diesem Zusammenhang wurden $\alpha$ - und $\beta$-Synuclein als potente Inhibitoren der Phospholipase D2 (nahe der Plasmamembran lokalisiert) isoliert (Jenco et al. 1998).

Als möglicher Entstehungsweg des PD könnte eine Kombination aus oxidativem Stress und der getriggerten Fehlfunktion von $\alpha$-Synuclein durch eine gestörte Vesikelfunktion zum Untergang von dopaminergen Zellen führen. Eine Fehlfunktion von $\alpha$-Synuclein kann auf mehreren Wegen zum neuronalen Zellschaden führen: zum einen können Aggregate gebildet werden, zum anderen können Interaktionen mit anderen Proteinen zum Zellschaden führen. Mutationen im Gen für $\alpha$-Synuclein führen zu einer Anhäufung von fibrillären $\alpha$ Synuclein-Strukturen in den LB (Spillantini et al. 1997).

Es wird zudem vermutet, dass $\alpha$-Synuclein auch mit Dopamin Bindungen eingehen kann, die die fibrillären Strukturen der in den LB vorkommenden Aggregate verstärken. Hierdurch wird der Untergang der dopaminergen Neurone in der Pathogenese des PD vermutet (Duda et al. 2002; Kahle und 
Haass 2004). Im Jahre 1993 konnte gezeigt werden, dass in den Plaques bei $A D$ die kurze NAC-Region von einem größeren Protein verdrängt wurde. Dieses wurde als humanes $\alpha$-Synuclein identifiziert (Uéda et al. 1993). Bereits vier Jahre später konnte ein Zusammenhang zwischen Mutation ALA53THR und dem early-onset-Parkinson hergestellt werden (Polymeropoulus et al. 1997). Im darauf folgenden Jahr verifizierten Kruger et al. eine weitere Mutation an ALA30PRO, wobei auch hier ein Zusammenhang bei der Entstehung des PD vermutet wird (Kruger et al. 1998). Durch die N-terminale Region (1-65) und deren Eigenschaften bindet $\alpha$-Synuclein an negativ geladene Phospholipide. Einige Studien haben gezeigt, dass eine lipophile Umgebung dazu führt, dass $\alpha$-Synuclein Aggregate bildet und somit bei der Entstehung von neurodegenerativen Erkrankungen beteiligt ist (Lee et al. 2002; Conway et al. 2001). Die N-terminale Domäne beinhaltet auch zwei für die Krankheitsentstehung des PD wichtige Mutationen: A30P und A53T. Diese können dazu führen, dass das Protein leichter in den verknäulten Zustand übergeht und zur B-Faltblatt Form führt, die wiederum leichter Aggregate und Filamente entstehen lässt (Li und Fink 2001).

Auf der Basis von Kopplungsanalysen in großen Familien mit Mendelscher Vererbung von Parkinson wurden bisher 11 chromosomale Stellen, sogenannte Loci, definiert. Sie werden mit der Abkürzung Park 1-11 bezeichnet (WoodKaczmar et al. 2006).

Für die folgende Arbeit sind besonders die Loci Park1 und Park 4 von größter Bedeutung, da diese mit der chromosomalen Lokalisation 4q21-23 bei Mutationen eine Veränderung im Gen für Synuclein hervorrufen können und so bei der Entstehung eines PD mitwirken können (Kruger et al. 1998). Es wurden bisher 3 Punktmutationen in dem das $\alpha$-Synuclein kodierenden Gen gefunden, eine Ala53THR-Mutation, eine Ala30Pro-Mutation und eine Gly46Lys-Mutation (Cookson 2005). Es wurde gezeigt, dass eine Verdopplung oder Verdreifachung der Loci für $\alpha$-Synuclein zur Entstehung eines early-onsetParkinson führen kann (Farrer et al. 2004; Nishioka et al. 2006; Singleton et al. 2003). Das Lebensalter bei Auftreten des Morbus Parkinson hängt mit der 
Anzahl der Loci zusammen. Eine Verdopplung des Locus, was zu 3 Kopien des $\alpha$-Synucleins führt, tritt in der 4. bis 5. Dekade auf, eine Verdreifachung des Locus, was wiederum zu vier Kopien führt, hingegen schon in der 2. bis 3. Dekade (Farrer et al. 2004; Singleton et al. 2003; Nishioka et al. 2006). 


\subsection{Zielsetzung}

Viele Studien haben sich bisher mit dem Einfluss von Infektionen auf die Auswirkung neurodegenerativer Erkrankungen beschäftigt. Diese Daten haben uns dazu veranlasst, in der vorliegenden Arbeit mit rezidivierenden extrazerebralen Infektionen mit S. pneumoniae den Einfluss an Infektionen auf eine der häufigsten neurodegenerativen Erkrankungen, den PD, im Tiermodell zu untersuchen.

Zum einen sollte die klinische Auswirkung mehrerer Infektionen mit S. pneumoniae auf den Beginn und den zeitlichen Verlauf des Morbus Parkinson untersucht werden. Hierzu wurden A30P-Mäuse mit S. pneumoniae infiziert, um die Auswirkung anhand von klinischen Tests zu untersuchen. Als klinische Testverfahren wurden der klinische Score, der Rotarod-Test und der Seiltest gewählt.

Zum anderen sollten die Veränderungen am Nervengewebe der Mäuse untersucht werden, was mit histologischen und immunhistochemischen Verfahren an Gehirn und Rückenmark verifiziert wurde.

Dabei sollte geklärt werden, inwieweit sich objektivierbare Unterschiede in den einzelnen Gruppen (Kontrollgruppe vs. Infektionsgruppe) in Bezug auf den Beginn und die Progredienz einer neurodegenerativen Erkrankung, in dieser Studie in Bezug auf den Morbus Parkinson, ergeben. 


\section{Material und Methoden}

\subsection{Material}

\subsubsection{Geräte}

Folgende Geräte wurden für die Durchführung der vorliegenden Arbeit verwendet (Tabelle 1):

\begin{tabular}{|l|l|}
\hline Gerät & Hersteller \\
\hline Blotkammer & $\begin{array}{l}\text { Amersham, Bioscience (Freiburg, } \\
\text { Deutschland) }\end{array}$ \\
\hline Brutschrank (Inkubator) & Heraeus (Hannover, Deutschland) \\
\hline Einbettautomat & Roth (Karlsruhe, Deutschland) \\
\hline Elektrophoresekammer & $\begin{array}{l}\text { Hoefer Scientific Instruments (Hollishen, } \\
\text { USA) }\end{array}$ \\
\hline Entwicklungskammer 18x24 & Siemens (Karlsruhe, Deutschland) \\
\hline Gelkammer & $\begin{array}{l}\text { Hoefer Scientific Instruments (Hollishen, } \\
\text { USA) }\end{array}$ \\
\hline Inkubationskammer & Heraeus (Hannover, Deutschland) \\
\hline Photometer & Labsystems (Quickborn, Deutschland) \\
\hline Rotarod Acceler & $\begin{array}{l}\text { TSE-Systems (Bad Homburg, Deutsch- } \\
\text { land) }\end{array}$ \\
\hline Rüttelplatte & Biometra (Göttingen, Deutschland) \\
\hline Schlitten-Mikrotom & Leica (Nussbach, Deutschland) \\
\hline Seil/Seiltest & Obi-Baumarkt (Göttingen, Deutschland) \\
\hline Waage & Sartorius (Göttingen, Deutschland) \\
\hline Zentrifuge & \begin{tabular}{l} 
Jouan (St. Herblain, Frankreich) \\
\hline
\end{tabular} \\
\hline
\end{tabular}

Tabelle 1: verwendete Geräte zur Durchführung der vorliegende Studie inklusive Herstellernachweis 


\subsubsection{Verbrauchsmittel}

In der folgenden Tabelle sind die in dieser Studie verwendeten Verbrauchsmittel mit Herstellernachweis aufgeführt (Tabelle 2).

\begin{tabular}{|c|c|}
\hline Verbrauchsmittel & Hersteller \\
\hline Blut-Agarplatte & Falcon (Heidelberg, Deutschland) \\
\hline Deckgläschen 20 x 20 & Menzel (Darmstadt, Deutschland) \\
\hline Einbettkassetten & Roth (Karlsruhe, Deutschland) \\
\hline Einmalspritze $1 \mathrm{ml}$ & Braun (Melsungen, Deutschland) \\
\hline Eppendorf-Cups & Eppendorf (Hamburg, Deutschland) \\
\hline Falcon-Tubes & Falcon (Heidelberg, Deutschland) \\
\hline Gel-Blotting-Papier & $\begin{array}{l}\text { Schleicher \& Schuell (Dassel, Deutsch- } \\
\text { land) }\end{array}$ \\
\hline Gießschälchen & Leica (Nussbach, Deutschland) \\
\hline Injektionskanüle Sterican 27G & Braun (Melsungen, Deutschland) \\
\hline Kryoröhrchen / Kryoboxen & Greiner (Frickenhausen, Deutschland) \\
\hline Mikrowell-Platte, 96-Loch & Sarstedt (Newton,USA) \\
\hline Objektträger & Menzel (Darmstadt, Deutschland) \\
\hline Pinzetten & Rettberg (Göttingen, Deutschland) \\
\hline Pipette (Glas) & Brandt (Wertheim, Deutschland) \\
\hline Mikrowelle & Panasonic (Hamburg, Deutschland) \\
\hline Sterilbank-Laminair ${ }^{\Theta}$ & Heraeus (Hannover, Deutschland) \\
\hline Stoppuhr & Casio (London, UK) \\
\hline Pipettenspitzen & Eppendorf (Hamburg, Deuschland) \\
\hline
\end{tabular}




\begin{tabular}{|l|l|}
\hline Protan Nitrocellulose Transfer Membran & $\begin{array}{l}\text { Schleicher \& Schuell (Dasseln, Deutsch- } \\
\text { land) }\end{array}$ \\
\hline Pinsel & Wiederholdt (Göttingen, Deutschland) \\
\hline Petrischale & Falcon (Heidelberg, Deutschland) \\
\hline Scheren & Rettberg (Göttingen, Deutschland) \\
\hline Skalpell & Rettberg (Göttingen, Deutschland) \\
\hline
\end{tabular}

Tabelle 2: in dieser Studie verwendete Verbrauchsmittel inkl. Herstellernachweis

\subsubsection{Chemikalien und Reagenzien}

Verwendete Chemikalien (Tabelle 3):

\begin{tabular}{|c|c|}
\hline Chemikalie & Hersteller \\
\hline Acrylamidstammlösung (30\%t;2,6\%c) & $\begin{array}{l}\text { AppliChem Biochemica (Darmstadt, } \\
\text { Deutschland) }\end{array}$ \\
\hline Aqua (bi) destillata & Merck (Darmstadt, Deutschland) \\
\hline Avidin & Vektor (Burlingame, Kanada) \\
\hline Ceftriaxon & Roche (Mannheim, Deutschland) \\
\hline 1,4-Dithiothreitol (DTT) & Merck (Darmstadt, Deutschland) \\
\hline Essigsäure & Merck (Darmstadt, Deutschland) \\
\hline Ethylendiamintetraacetat (EDTA) & Merck (Darmstadt, Deutschland) \\
\hline $\begin{array}{l}\text { Ethyleneglycol-bis( } \beta \text {-aminoethyl)-N,N,N', } N^{\prime} \text { - } \\
\text { tetraacetic Acid (EGTA) }\end{array}$ & Merck (Darmstadt, Deutschland) \\
\hline Formaldehyd & Merck (Darmstadt, Deutschland) \\
\hline Fötales Kälberserum & Gibco (Paysley, Schottland, UK) \\
\hline Kupfersulfat $4 \%\left(\mathrm{CuSO}_{4}\right)$ & Merck (Darmstadt, Deutschland) \\
\hline Magermilchpulver & Merck (Darmstadt, Deutschland) \\
\hline Methanol / Ethanol & Merck (Darmstadt, Deutschland) \\
\hline MOPS & Merck (Darmstadt, Deutschland) \\
\hline $\begin{array}{l}N, N, N^{\prime}, N^{\prime} \text {-Tetramethylethan-1,2-diamin } \\
\text { (TEMED) }\end{array}$ & $\begin{array}{l}\text { Santa Cruz (Heidelberg, Deutsch- } \\
\text { land) }\end{array}$ \\
\hline Natriumbicarbonat & Merck (Darmstadt, Deutschland) \\
\hline
\end{tabular}




\begin{tabular}{|c|c|}
\hline Natriumcarbonat & Merck (Darmstadt, Deutschland) \\
\hline Natriumchlorid ( $\mathrm{NaCl})$ & Roche (Mannheim, Deutschland) \\
\hline Citronensäure-Monohydrat & Merck (Darmstadt, Deutschland) \\
\hline Dimethylformamid & Sigma (Deisenhofen, Deutschland) \\
\hline Nitronblau-Tetrazolin & Roche (Mannheim, Deutschland) \\
\hline Natriumdodecylsulfat (SDS) & Merck (Darmstadt, Deutschland) \\
\hline Natriumtartrat & Merck (Darmstadt, Deutschland) \\
\hline Natronlauge $(\mathrm{NaOH})$ & Merck (Darmstadt, Deutschland) \\
\hline Paraffin (Paraplast) & Kendall (Mansfield, USA) \\
\hline PBS-Puffer & Bichrom (Berlin, Deutschland) \\
\hline PMSF & Merck (Darmstadt, Deutschland) \\
\hline Sucrose & Merck (Darmstadt, Deutschland) \\
\hline TBS-Puffer & Bichrom (Berlin, Deutschland) \\
\hline Tricine & Merck (Darmstadt, Deutschland) \\
\hline Trishydroxymethylaminomethan (Tris) & Roth (Karlsruhe, Deutschland) \\
\hline Triton $\mathrm{X}-100$ & Sigma (Deisenhofen, Deutschland) \\
\hline Tween-20 & Sigma (Deisenhofen, Deutschland) \\
\hline Wasserstoffperoxid & Merck (Darmstadt, Deutschland) \\
\hline$\overline{X y l o l}$ & Merck (Darmstadt, Deutschland) \\
\hline
\end{tabular}

Tabelle 3: verwendete Chemikalien, inklusive Herstellernachweis

Für Färbungen wurden folgende Reagenzien genutzt (Tabelle 4):

\begin{tabular}{|c|c|}
\hline Färbereagenz & Hersteller \\
\hline $\begin{array}{l}\text { Bromphenolblau }\left(3^{\prime}, 3^{\prime \prime}, 5^{\prime}, 5^{\prime \prime} \text {-Tetrabromophenol- }\right. \\
\text { sulfonphthalein) }\end{array}$ & $\begin{array}{ll}\text { Sigma } & \text { (Deisenhofen, } \\
\text { Deutschland) } & \end{array}$ \\
\hline Hämalaun & Merck (Darmstadt, Deutschland) \\
\hline
\end{tabular}




\begin{tabular}{|l|l|}
\hline Hämatoxylin, Eosin & Merck (Darmstadt, Deutschland) \\
\hline Immu-Mount & Thermo (Pittsburgh, USA) \\
\hline Isolectin B4 & $\begin{array}{l}\text { Sigma } \\
\text { Deutschland) }\end{array}$ \\
\hline
\end{tabular}

Tabelle 4: Färbereagenzien, inklusive Herstellernachweis

Zur Herstellung des Proteaseinhibitorcocktails (PIC) wurden die folgenden Antiproteasen eingesetzt (Tabelle 5):

\begin{tabular}{|l|l|}
\hline Antiprotease & Hersteller \\
\hline Aprotinin $\left(\right.$ Trasylol $^{\circledR}$ ) & $\begin{array}{l}\text { Bayer Pharmaceutics (Leverkusen, } \\
\text { Deutschland) }\end{array}$ \\
\hline Leupeptin & Roche (Mannheim,Deutschland) \\
\hline Pepstatin & Roche (Mannheim, Deutschland) \\
\hline PMSF (Phenylmethylsulfonylfluorid) & Roche (Mannheim, Deutschland) \\
\hline
\end{tabular}

Tabelle 5: Antiproteasen zur Herstellung des Proteaseninhibitorcocktails, inkulsive Herstellernachweis

\subsubsection{Bakterium}

Für die Infektion wurde ein Streptococcus pneumoniae Serotyp 3 verwendet. Dieses wurde aus dem Liquor eines erwachsenen Patienten mit Meningitis isoliert und freundlicherweise von Prof. Dr. med. M. G. Täuber, Universität Bern/Schweiz, für diese Arbeit zur Verfügung gestellt.

\subsubsection{Antibiotikum}

Als Antibiotikum wurde ein Cephalosporin der 3. Generation verwendet: Ceftriaxon (Rocephin ${ }^{\circledR} /$ Firma Roche). Ceftriaxon, bekannt auch unter $(6 \mathrm{R}, 7 \mathrm{R})$ 7-[(Z)-2-(2-Amino-4-thiazolyl)-2-methoxyiminoglyoxylamido]-3-\{[(2,5-dihydro-6hydroxy-2-methyl-5-oxo-1,2,4-triazin-3-yl)thio]methyl\}-8-oxo-5-thia-1azabicyclo[4.2.0]oct-2-en-2-carbonsäure, ist ein Antibiotikum aus der Gruppe der Cephalosporine der 3. Generation (Abbildung 1). Ceftriaxon wurde 1982 unter dem Handelsnamen Rocephin ${ }^{\circledR}$ von Hoffmann-La Roche eingeführt. 
<smiles>CO/N=C(\C(=O)N[C@H]1C(=O)N2C(C(=O)O)=C(CSc3nc(=O)c(=O)[nH]n3C)CSC[C@@H]12)c1csc(N)n1</smiles>

Abbildung 1: $\mathrm{C}_{18} \mathrm{H}_{16} \mathrm{~N}_{8} \mathrm{Na}_{2} \mathrm{O}_{7} \mathrm{~S}_{3} \cdot 3.5 \mathrm{H}_{2} \mathrm{O}$ oder auch Ceftriaxon (O'Neil, 2006)

Ceftriaxon kann ausschließlich parenteral appliziert werden, da eine Resorption bei oraler Gabe nicht stattfindet. Die Halbwertszeit von Ceftriaxon beträgt auf Grund einer hohen Plasmaproteinbindung 7-8 Stunden. Ceftriaxon ist ausreichend gewebegängig und erreicht auch im Liquor cerebrospinalis therapeutisch wirksame Konzentrationen und ist zur kalkulierten Initialtherapie schwerster, lebensbedrohlicher Infektionen, einschließlich der eitrigen Meningitis geeignet. Weiterhin findet es in der Therapie der Neuroborreliose und der Gonorrhoe (Einmalbehandlung) Verwendung (O'Neil 2006).

\subsubsection{Antikörper}

Folgende Antikörper wurden in dieser Studie verwendet (Tabelle 6):

\begin{tabular}{|l|l|}
\hline Bezeichnung/Firma & Hersteller \\
\hline Anti-Maus-IgG-Antikörper (Schaf) & Amersham (Freiburg, Deutschland) \\
\hline $\begin{array}{l}\text { Vectastatin-ABC (Avidin-Biotin- } \\
\text { Komplex) }\end{array}$ & Vecton (Burhingame, Kanada) \\
\hline
\end{tabular}

Tabelle 6: Antikörper, inklusive Herstellernachweis 


\subsubsection{Kits und Assays}

Folgende Kits und Assays wurden in der vorliegenden Studie verwendet (Tabelle 7):

\begin{tabular}{|l|l|}
\hline Bezeichnung & Hersteller \\
\hline BCA & $\begin{array}{l}\text { Der BCA- Assay wird mit dem BCA-Protein-Assay-Kit der Fir- } \\
\text { ma Pierce (Illinois, USA) durchgeführt. }\end{array}$ \\
\hline
\end{tabular}

Tabelle 7: Kits und Assays, inklusive Herstellernachweis

\subsubsection{Pufferlösungen}

Folgende Pufferlösungen wurden in der vorliegenden Studie verwendet:

Citratpuffer $10 \mathrm{mmol}$ Zitronensäure-Monohydrat in Aqua dest., auf $\mathrm{ph}=6,0$ eingestellt

Phosphate-bufferd-saline (PBS)-Puffer 9,55g PB1 in 1 Liter Aqua dest.

Tris-bufferd-saline (TBS)-Puffer $50 \mathrm{mmol}$ Tris und $150 \mathrm{mmol} \mathrm{NaCl}$ in Aqua dest., auf $\mathrm{pH}=7,0$ eingestellt 


\subsection{Methoden}

\subsubsection{Tiere}

Für diese Studie wurden transgene Mäuse (C57BL/6 Mäusestamm) genutzt, die freundlicherweise von Herrn Dr. Christoph Dohm (Georg-August-Universität zu Göttingen) zur Verfügung gestellt wurden. Sie weisen zwischen dem 6. und 14. Lebensmonat klinische Symptome der Parkinson-Erkrankung auf, beginnend mit Tremor bis hin zur muskulären Rigidität, zu haltungsbedingten Instabilitäten und Paralyse (Kahle et al. 2000; Frasier et al. 2005).

Die Mäuse wurden in Käfigen von 3-6 Tieren pro Käfig gehalten, männliche von weiblichen Tieren getrennt, in einem Raum mit einem 12 Stunden-Tag/NachtRhythmus. Alle Tiere hatten freien Zugang zu Essen und Trinken.

Die Tierexperimente wurden durch die Tierschutzkommisson der Universitätsklinik Göttingen befürwortet und durch das Niedersächsische Landesamt für Verbraucherschutz und Lebensmittelsicherheit (LAVES) genehmigt.

\subsubsection{Inokulum}

Genutzt wird ein S. pneumoniae Serotyp 3, der mittels Passage im Kaninchen vermehrt wurde, um die Virulenz des Erregers über einen längeren Zeitraum zu erhalten. Das Bakterium wurde mit einer Menge von $3 \times 10^{5} \mathrm{CFU}$ dem Kaninchen (New Zealand Rabbit) intrathekal verabreicht. Nach 18-24 Stunden wurde dem Tier Liquor entnommen und 1 zu 10 mit $\mathrm{NaCl}$ verdünnt. Diese Lösung wurde auf Blutagarplatten aufgetragen und für 24 Stunden im Brutschrank bei $37^{\circ} \mathrm{C}$ inkubiert. Die Kolonien wurden mit $1 \mathrm{ml} 0.9 \% \mathrm{NaCl}$ abgelöst, in den gewünschten Mengen aliquotiert und bei $-80^{\circ} \mathrm{C}$ eingefroren. Durch Verdünnung mit der entsprechenden Menge $0,9 \% \mathrm{NaCl}$ erhält man die gewünschte Keimzahl. Um die in dieser Arbeit verwendete Lösung herzustellen, wurden $10 \mu \mathrm{l}$ auf $10 \mathrm{ml} 0,9 \% \mathrm{NaCl}$ verdünnt und dann intraperitoneal injiziert. 
Das Inokulum wurde für die vorliegende Studie so verdünnt, dass eine Konzentration des S. pneumoniae von 2-3 $\times 10^{5}-1 \times 10^{6} \mathrm{CFU} / \mathrm{ml}$ erreicht wurde (Tabelle 8).

Die genutzte Verdünnungsreihe sieht wie folgt aus:

\begin{tabular}{|l|l|l|l|}
\hline & Inokulum in $\boldsymbol{\mu l}$ & $\begin{array}{l}\mathbf{0 , 9} \% \mathrm{NaCl} \text { in } \\
\boldsymbol{\mu l}\end{array}$ & $\begin{array}{l}\text { Konzentration } \\
\text { (CFU/ml) }\end{array}$ \\
\hline A & 10 & 90 & $10^{-3}$ \\
\hline B & 50 von A & 450 & $10^{-4}$ \\
\hline C & 50 von B & 450 & $10^{-5}$ \\
\hline D & 50 von C & 450 & $10^{-6}$ \\
\hline E & 50 von D & 450 & $10^{-7}$ \\
\hline F & 50 von E & 450 & $10^{-8}$ \\
\hline G & 50 von F & 450 & $10^{-9}$ \\
\hline H & 50 von G & 450 & $10^{-10}$ \\
\hline
\end{tabular}

Tabelle 8: Verdünnungsreihe des Inokulums

\subsubsection{Infektion}

Für die Infektionen (Peritonitis und Sepsis) wurde den Versuchstieren (Infektionsgruppe) 0,5 ml der Infektionslösung mit einer G27 x 1/2“, 0,4 x 12 $\mathrm{mm}$ Kanüle intraperitoneal injiziert. Die Tiere der nicht infizierten Gruppe (Kontrolle) erhielten die entsprechende Menge $0.9 \% \mathrm{NaCl}$.

Eine Peritonitis und eine Sepsis wurden durch eine intraperitoneale Applikation von $2.5 \times 10^{5} \mathrm{CFU} / \mathrm{ml} \mathrm{S}$. pneumoniae erreicht.

Die Injektion wurde einmal im Monat durchgeführt. Hierzu wurden alle Tiere gewogen, um einen eventuellen Gewichtsverlust (als Folge einer Infektion) zu registrieren. Dann wurden der Gruppe der zu infizierenden Tiere (Infektionsgruppe) 0,5 ml Inokulum und der Gruppe der Kontrolltiere (Kontrollgruppe) $0,5 \mathrm{ml} 0.9 \% \mathrm{NaCl}$ verabreicht. 
Die erste Infektion fand im Alter von 2 bzw. 6 Monaten statt. Insgesamt wurden 12 Injektionen im Abstand von einem Monat gesetzt.

Nach jeder Infektion wurde die Konzentrationen des Inokulums überprüft. Hierzu wurde die zur Infektion angesetzte Lösung ausgeplattet und für mind. 24 Std. bei $37^{\circ} \mathrm{C}$ inkubiert und dann die gewachsene Keimzahl abgelesen.

Die erste Gabe des Antibiotikums (100mg/kg, Wirkstoff: Ceftriaxon-Dinatrium 3,5 $\mathrm{H}_{2} \mathrm{O}$ ) wurde 12 Stunden post infektionem gegeben, da man eine latente Stimulation des Immunsystems erreichen wollte. Die Wahl des Antibiotikums (Rocephin) erfolgte auf Grund der langen Plasma-Halbwertszeit mit einer Eliminationshalbwertszeit von 8 Stunden, was eine gute Handhabung während des gesamten Versuches gewährleisten sollte.

Es fanden insgesamt 6 Gaben des Antibiotikums statt, die in einem 12 Stunden Intervall gegeben wurden. Die Mäuse wurde vor jeder Gabe des Antibiotikums gewogen, um die genaue Menge des Antibiotikums berechnen zu können.

\subsubsection{Testverfahren}

Um den Krankheitszustand der Tiere beurteilen zu können, wurde ein Score gewählt, der einen Vergleich der Mäuse zulässt. Als klinischer Score wurde ein Zahlenwert zwischen 0-4 erhoben. Der Score setzte sich folgendermaßen zusammen (Tabelle 9):

\begin{tabular}{|l|l|}
\hline Punktwert & Klinischer Score \\
\hline $\mathbf{0}$ & Gesund \\
\hline $\mathbf{1}$ & pathologischer Reflex der Hinterbeine bei Anheben am Schwanz \\
\hline $\mathbf{2}$ & Erste leichte Lähmungserscheinungen der Extremitäten \\
\hline $\mathbf{3}$ & $\begin{array}{l}\text { schwere Lähmungserscheinungen der Extremitäten } \\
\text { das Tier kann sich nicht mehr innerhalb von 30 Sekunden aus der Seit- } \\
\text { oder Rückenlage alleine aufrichten. }\end{array}$ \\
\hline $\mathbf{4}$ &
\end{tabular}

Tabelle 9: Punktwert des klinischen Scores 
Der Score wurde bis zum Erreichen eines Wertes von "1" zwei bis drei Mal in der Woche erhoben. Ab Erreichen eines Punktwertes von "1“ (symptomatisch) wurde das erkrankte Tier täglich untersucht. Um den Score zu erheben, wurden die Tiere am Schwanz hochgehoben und auf die oben beschriebenen Veränderungen untersucht.

Der Seiltest wurde verwendet, um die motorischen Fähigkeiten der Tiere zu untersuchen. Hierfür wurde ein $60 \mathrm{~cm}$ langes Seil $60 \mathrm{~cm}$ über dem Boden aufgespannt. Eine Box mit weichem Untergrund wurde zum Abfangen eines möglichen Falles der Maus unter das Seil gestellt. Die Mäuse wurden am Schwanz aufgenommen und mit ihren Vorderläufen in der Mitte des $60 \mathrm{~cm}$ langen Seiles aufgehängt. Gemessen wurde die Zeit, die die Tiere benötigen, um das Ende eines Seiles zu erreichen. Die gesunden Tiere versuchten nach vorherigem Training, eine der Plattformen an einem der Seilenden zu erreichen. Dazu wurden alle 4 Pfoten und der Schwanz zu Hilfe genommen. Die erkrankten Tiere wiesen Defizite im Einsatz ihrer Extremitäten oder des Schwanzes auf und benötigten deutlich mehr Zeit, um die Plattform, und damit das Seilende zu erreichen. Die Auswertung erfolgte mittels des Wellmer Scores, der den Einsatz der Extremitäten und des Schwanzes in Kombination mit der benötigten Zeit (gemessen mit einer Stoppuhr) berücksichtigt (Wellmer et al. 2000). Im Folgenden werden die einzelnen Parameter des Tests aufgeführt: Erreichte das Tier das Ende des Seiles in einer bestimmten Zeit, wurde ein Score vergeben (minimum score 0; maximum score 20) (Tabelle 10). Mäuse, die das Ende in weniger als 6 Sekunden erreichten, bekamen den Score 0. Ein zusätzlicher Punkt wurde vergeben für jeweils weitere 6 Sekunden, die das Tier benötigte. Mäuse, die mehr als 60 Sekunden am Seil hingen und das Ende nicht erreichten, bekamen den Score 10. Tiere, die früher herunterfielen, bekamen einen zusätzlichen Punkt für jede 6 Sekunden vor der Endzeit (60s) zum Maximalscore von 10 hinzugerechnet. Ein niedriger Score beschreibt somit eine gute motorische Leistung. 


\begin{tabular}{|l|l|l|l|l|}
\hline Zeit & Score & & Zeit & Score \\
\hline Maus schafft es & & & $\begin{array}{l}\text { Maus schafft es } \\
\text { nicht }\end{array}$ & \\
\hline $0-6 s$ & 0 & & hängt > 60s & 10 \\
\hline $7-12 s$ & 1 & & hängt 59-54s & 11 \\
\hline $13-18 s$ & 2 & & Hängt 53-48s & 12 \\
\hline $19-24 s$ & 3 & & Hängt 41-36s & 14 \\
\hline $25-30 s$ & 4 & & Hängt 35-30s & 15 \\
\hline $31-36 s$ & 5 & & Hängt 29-24s & 16 \\
\hline $37-42 s$ & 6 & & Hängt 23 - 18s & 17 \\
\hline $43-48 s$ & 7 & & Hängt 17-12s & 18 \\
\hline $49-54 s$ & 8 & & Hängt 11 - 6s & 19 \\
\hline $54-60 s$ & 9 & Hängt < 6s & 20 \\
\hline & & & & 13 \\
\hline
\end{tabular}

Tabelle 10: Seiltest-Score nach Wellmer et al 2000

Der Rotarod-Test dient zur Überprüfung des motorischen und koordinativen Leistungsvermögens sowie der Kraft des Versuchstieres. Für diesen Test wurde ein Rotarod-Gerät (Neuroscience Inc. Tokyo/Japan) verwendet, mit einer einzelnen Parzelle (Durchmesser 2,8cm) für jedes Tier. So konnten bis zu 5 Tiere gleichzeitig getestet werden. Die Tiere wurden vor dem ersten Test trainiert, auf dem Rotarod-Gerät zu laufen. Die Mäuse wurden auf eine Rolle (in einzelner Parzelle) gesetzt, die mit 4 Umdrehungen pro Minute rotiert und auf bis zu 40 Umdrehungen pro Minute beschleunigt werden kann (Modus: „accelerate“). Um auf der Rolle zu laufen, muss die Maus entgegen der Drehrichtung der Rolle zu laufen beginnen. Diese Technik wurde den Versuchstieren über 1-2 Wochen antrainiert. Die Mäuse wurden auf die Rolle gesetzt und mussten auf der Einstellungsoption "accelerate“ maximal 300 Sekunden laufen. Fiel ein Tier herunter, wurde dies vom Gerät registriert und aufgezeichnet. Je länger die Verweildauer auf dem Gerät betrug, desto höher 
die motorische Leistung (Bailey et al. 2006; Caston et al. 1998; Lalonde et al. 1995).

\subsubsection{Gewebeaufbereitung}

Die Mäuse wurden bei Erreichen eines der Abbruchkriterien (aktuelles Gewicht $<15 \%$ des Maximalgewichts, Krankheits-Score 4 oder Erreichen des 12. bzw. 18. Monats) durch einen Genickbruch getötet.

\subsubsection{Gehirn, Präparation, Paraffin}

Nachdem der Kopf des Tieres mit einer Schere abgetrennt worden war, erfolgte die Freilegung des knöchernen Schädels durch Eröffnen und Präparation der Kopfhaut an der Medianlinie. Nachfolgend wurde der Schädel in der Medianlinie bis zur hinteren Schädelnaht aufgeschnitten, das Gehirn mit Hilfe des Skalpells freigelegt und aus der Kalotte herauspräpariert. In der Sagittalebene wurde das Gehirn in zwei Teile durchtrennt. Die linke Gehirnhälfte wurde für die Immunhistochemie in 4\% Formalinlösung für 2 Tage gestellt und danach bis zur Paraffinierung in PBS aufbewahrt. Die rechte Gehirnhälfte wurde in drei Teile geteilt: Cerebellum; anteriore Kortexhälfte und posteriore Kortexhälfte. Alle drei Teile wurden in jeweils ein E-Cup mit Sicherheitsverschluss gegeben, in flüssigem Stickstoff schockgefroren und dann bei $-80^{\circ} \mathrm{C}$ aufbewahrt.

Die Homogenisierung wurde am selben Tag der Präparation durchgeführt. War dieses nicht möglich, wurde das Gehirn langsam bis $-80^{\circ} \mathrm{C}$ eingefroren, um möglichst wenig Eiweißstruktur zu zerstören. Die zur Homogenisierung verwendeten Geräte müssen mindestens einen Tag zuvor gewaschen und getrocknet werden. Dazu wurden die Glasmörser und Gefäße für 1 Stunde in $\mathrm{NaOH}$ eingelegt. Danach wurde alles gründlich mit Aqua destillata gewaschen und für mindestens eine Stunde in Ameisensäure eingelegt. Danach erfolgte eine erneute Spülung mit Aqua destillata. Im Anschluss wurden die Mörser und Gefäße zum Trocknen aufgestellt und konnten am nächsten Tag zur Homogenisierung verwendet werden. Zur Homogenisierung wurde ein Homogenisator mit einem Glasmörser verwendet. Die zu bearbeitende Hirnhälfte wurde zuvor auf einer Feinwaage gewogen und im Verhältnis 1:10w/v mit einem Puffer (10mM MOPS/NaOH $\mathrm{pH} 7,4 ; 0,32 \mathrm{M}$ Saccharose; 
$1 \mathrm{mM}$ EDTA; $1 \mathrm{mM}$ EGTA) versetzt. Das Gehirn wurde mit dem Glasmörser zermörsert. Anschließend wurde das Homogenat bei $-80^{\circ} \mathrm{C}$ in Aliquots zu je $100 \mu$ l eingefroren.

\subsubsection{Proteinextraktion}

Die Probe wurde langsam im Kühlschrank aufgetaut und unmittelbar im Anschluss mit einem Lysispuffer (150 mM NaCl; $50 \mathrm{mM}$ Tris pH 8,0; 1\% Triton X 100; 0,2 mM EDTA; 2 mM PMSF; $1 \mu$ M Pepstatin; $10 \mu$ Leupeptin; $2 \mu \mathrm{g} / \mathrm{ml}$ Aprotinin) versetzt. Nach einer Wartezeit von 20 Minuten bei Raumtemperatur wurde die Probe bei $4^{\circ} \mathrm{C} 15 \mathrm{~min}$ bei 18000 upm zentrifugiert. Anschließend wurde der Überstand abpipettiert und aliquotiert. Die Probe wurde mit dem BCA-Assay auf ihren Eiweißgehalt geprüft.

\subsubsection{BCA-Protein-Assay}

Zur Bestimmung der Proteinkonzentration wurde der BCA-Assay gewählt. Mit dieser Methode kann man zeitgleich mehrere Proben unter gleichen Bedingungen testen. Die Proteinbestimmung basiert auf einer Farbreaktion (Lilafärbung), die man photometrisch messen kann.

Diese Farbänderung kommt dadurch zustande, dass die Peptidbindungen und Aminosäuren nach Zugabe von Bicinchonsäure (BCA) eine Farbänderung hervorrufen. BCA ist ein Reagenz, das sehr sensibel und spezifisch für Kupferionen ist und die Biuretreaktion zur Bildung des Farbkomplexes nutzt (Lowry et al. 1951) (Abbildung 2).

$$
\text { Protein }+\mathrm{Cu}^{2+} \stackrel{\text { BCA-Prot-Assay-Reagenz }}{\mathrm{OH}^{-} \mathrm{H}_{2} \mathrm{O}} \mathrm{BCA}-\mathrm{Cu}^{+} \text {Komplex (lilafarben) }
$$

Abbildung 2: Reaktion zur Proteinbestimmung

Zur Durchführung wurde das BCA-Protein-Assay-Working-Reagenz (WR) angesetzt. Dieses besteht aus 50 Teilen Reagenz A (Natriumcarbonat; Natriumbikarbonat; BCA Detektionsreagenz; Natriumtartrat in $0,1 \mathrm{M} \mathrm{NaOH}$ ) und 
1 Teil Reagenz B (4\% Kupfersulfat). Als Standard wird die mitgelieferte BSALösung $(2000 \mathrm{ug} / \mathrm{ml})$ verwendet. Die Verdünnung erfolgt gemäß dem mitgelieferten Protokoll (Tabelle 11)

\begin{tabular}{|l|l|l|}
\hline Menge an BSA $\boldsymbol{\mu l}$ & $\begin{array}{l}\text { Menge an Bidest } \\
\boldsymbol{\mu l}\end{array}$ & Proteinkonzentration \\
\hline 300 & 0 & 2000 \\
\hline 375 & 125 & $1500(\mathrm{~A})$ \\
\hline 325 & 325 & $1000(\mathrm{~B})$ \\
\hline 175 von $\mathrm{A}$ & 175 & $750(\mathrm{C})$ \\
\hline 325 von $\mathrm{B}$ & 325 & $500(\mathrm{D})$ \\
\hline 325 von D & 325 & $250(\mathrm{E})$ \\
\hline 325 von $\mathrm{E}$ & 325 & $125(\mathrm{~F})$ \\
\hline 100 von $\mathrm{F}$ & 400 & $25(\mathrm{G})$ \\
\hline
\end{tabular}

Tabelle 11: Verdünnungsreihe für die Standardlösung BSA

Beide Lösungen wurden nach dem Protokoll des Kits generiert. Anschließend werden die Mikrowell Platten, wie im Protokoll beschrieben, mit der Standardlösung und der zu untersuchenden Probe beladen, indem man $25 \mu \mathrm{l}$ in die einzelnen Näpfe der Platte auftrug. Von der Probe wurden unterschiedliche Verdünnungen aufgetragen. In alle beladenen Näpfe der Platte wurden 200 $\mathrm{ll}$ der WR zugegeben. Nach einer Inkubationszeit von 2 Stunden bei Raumtemperatur von ca. $22^{\circ} \mathrm{C}$ wurde eine photometrische Messung der Wellenlänge durchgeführt und anhand der Standardkurve ein Diagramm erstellt, woran die genaue Eiweißmenge abgelesen und ausgerechnet werden konnte. Diese Werte benötigte man, um das Gel bei der Elektrophorese nicht mit Eiweiß zu überladen.

\subsubsection{ELISA - Enzyme-Linked Immunosorbent Assay}

ELISA - Enzymimmunoassay (EIA) bzw. Enzyme-Linked Immunosorbent Assay (ELISA) bezeichnet ein immunologisches Nachweisverfahren (Assay), das auf einer enzymatischen Farbreaktion basiert und zur Gruppe der 
Immunassay-Verfahren gehört. Mit Hilfe dieses Testverfahrens können Proteine, wie in der vorliegenden Arbeit auch, sowie niedermolekulare Verbindungen wie Hormone, Toxine etc. aus einer Probe (z.B.: Blutserum, Milch, Urin, Liquor etc.) nachgewiesen werden.

Eine der ELISA-Techniken (Sandwich-ELISA) verwendet zwei Antikörper (AK), die beide spezifisch an das nachzuweisende Antigen binden, Double-AntibodySandwich-ELISA.

Hierbei ist es wichtig, dass beide Antikörper an unterschiedlichen Stellen an das Antigen binden, da sie sich sonst gegenseitig behindern würden. Der erste Antikörper (coating-Antikörper) wird an eine feste Phase (meist spezielle 96Loch oder 384-Loch-Mikrotiterplatte - letztere wurde in der vorliegenden Arbeit genutzt) gebunden. Die Probe mit dem nachzuweisenden Antigen wird dann in die wells gegeben und eine protokollvorgegebene Zeit inkubiert. Während dieser Zeit bindet der an die Platte gebundene Antikörper das in der Probe vorhandene Antigen. Nach Ablauf der Inkubationsphase wird die Platte nach Protokoll gewaschen.

Die ungebundenen Bestandteile der Probe werden dadurch entfernt und zurück bleibt das am (coating-) Antikörper gebundene Antigen. Im nächsten Schritt wird ein Detektions-(detection)-Antikörper zugegeben, an dessen Ende ein Enzym (meistens Meerrettichperoxidase (HRP), Alkalische Phosphatase (AP) oder seltener Glucoseoxidase (GOX)) gebunden ist. Dieser zweite Antikörper bindet ebenfalls an das Antigen und es entsteht der Antikörper-AntigenAntikörper-Komplex (Sandwich-ELISA). Durch erneutes Waschen der Platte wird der überschüssige zweite Antikörper ausgewaschen und anschließend ein zum Enzym passendes chromogenes Substrat zugegeben. Dieses wird vom Enzym zu einem Reaktionsprodukt umgesetzt, dessen Nachweis durch Farbumschlag, Fluoreszenz oder Chemoluminiszenz erfolgen kann (Engvall und Perlman 1971; Goldsby et al. 2003).

Die erste Generation des spezifischen ELISA zur Quantifizierung des kompletten $\alpha$-Synucleins wurde erst kürzlich veröffentlicht und im Labor von 
Michael Schlossmacher mehrfach getestet (Tokuda et al. 2006; Mollenhauer et al. 2008). Die zweite Generation des spezifischen ELISA zur Quantifizierung des aus Liquor gewonnenen humanen $\alpha$-Synucleins wurde durch Mollenhauer et al. entwickelt und mit 384-well-Maxi-Sorp-Platten für diese Arbeit genutzt. Die gesamte Untersuchung mittels ELISA wurde freundlicherweise von Frau Dr. Brit Mollenhauer am Center für Neurologische Erkrankungen des Brigham und Women's Krankenhaus in Boston durchgeführt (Mollenhauer et al. 2008).

\subsubsection{Histologische Probenauswertung}

Die in Paraffin eingebetteten Schnitte wurden mit zwei verschiedenen Färbungen behandelt. Es wurden Schnitte von verschiedenen Ebenen des Gehirns angefertigt mit einer Dicke von 1-2 $\mu \mathrm{m}$. Für die Untersuchung des Morbus Parkinson ist der Bereich der Substantia nigra und des Hippokampus von großer Bedeutung. Die Schnitte, deren Dicke typischerweise bei 0,1$100 \mu \mathrm{m}$ (in der vorliegenden Arbeit $100 \mu \mathrm{m}$ ) liegt, wurden mit dem Microtom hergestellt und auf einen Objektträger aufgezogen. Anschließend konnten die Schnitte je nach ausgewählter Färbung weiterverwendet werden.

\subsubsection{Verwendete Färbungen}

Verwendete Färbungen in dieser Studie sind der Tabelle 12 zu entnehmen.

\begin{tabular}{|l|l|}
\hline \multicolumn{1}{|c|}{ Färbung } & \multicolumn{1}{c|}{ Darzustellende Struktur } \\
\hline Hämatoxylin-Eosin (HE) & Zellkerne, Plasma \\
\hline Isolektin B4 (IB4) & Aktivierte Mikroglia verschiedener Stadien \\
\hline
\end{tabular}

Tabelle 12: verwendete Färbungen der Gehirnschnitte

\subsubsection{Hämatoxylin-Eosin (HE)}

Hämatoxylin ist ein Inhaltsstoff des Blauholz (Haematoxylon campechianum) und verwandter Arten. In der Histologie wird Hämatoxylin zum Färben von Zellund Gewebestrukturen, wie z.B. Zellkernen, Mitochondrien, Myelin, Elastin und Kollagenfasern, eingesetzt.

In Kombination mit der Hämatoxylin-Färbung (H-Färbung, Zellkernfärbung) wird in der Regel eine Gegenfärbung mit einem kontrastreichen Zytoplasmafarbstoff 
durchgeführt. Klassisch wird eine Gegenfärbung mit Eosin durchgeführt, Hämatoxylin-Eosin-Färbung (HE-Färbung), bei der kationische/eosinophile Strukturen (z. B. Proteine) angefärbt werden. Hierbei werden Zellkerne üblicherweise dunkelblau eingefärbt, während die anderen Zellbestandteile hellrosa bis pink erscheinen. Eosin ist ein synthetischer saurer Farbstoff und färbt alle azidophilen beziehungsweise basischen (eosinophilen) Strukturen, vor allem die Zellplasmaproteine, rot.

Für die vorliegende Arbeit wurden die Proben in saurem Hämatoxylin nach Ehrlich oder alternativ in saurem Hämalaun nach Mayer angefärbt. Anschließend folgte das Bläuen in fließendem Leitungswasser oder alternativ in $0.25 \%$ iger Natriumhydrogencarbonatlösung und nachfolgend das Abspülen in Aqua destillata. Als nächster Schritt folgt die Färbung in einer wässrigen Lösung von Eosin, verdünnt mit Auqa destillata im Verhältnis 1:10 für 5-10 Minuten. Im Falle, dass der Farbstoff nicht auf das Gewebe aufziehen sollte, erfolgte die Zugabe von 1 Tropfen Eisessig zu 100ml der wässrigen Eosinlösung. Ein erneuter Spülschritt mit Aqua destillata erfolgte. Nachfolgend wurde die Probe durch weitere Spülschritte über Alkohollösungen in aufsteigender Konzentration bis zu absolutem Alkohol entwässert. Danach wurde der Schnitt in einem Intermedium, in der vorliegenden Arbei in Xylol, geklärt. Der Einschluss mittels Eindeckmittel und schlussendlich die Konservierung mittels Deckglas beendete den Färbevorgang (Woods und Ellis 1994-96).

Im Ergebnis zeigten sich nach erfolgreichem Färbevorgang die Zellkerne blauschwarz bis violett, die zytoplasmatischen Bestandteile färbten sich rosa-rot ein.

\subsubsection{Isolektin B4 (IB4)}

Isolektin B4 (IB4) ist ein 144kDa Glykoprotein und Teil der 5-Tetramer-Typ-I Isolektine (IA4, IA3B, IA2B2, IAB3, IB4), das aus dem Samen der afrikanischen Hülsenfrucht Griffonia simplicifolia (früher unter Bandeiraea simplicifolia bekannt) isoliert wurde. Die A- und B- Untereinheiten der einzelnen Proteine sind ähnlich und unterscheiden sich nur in der Aminosäurenfrequenz am N- 
Terminus. Jedoch weisen die Untereinheiten unterschiedliche Bindungsspezifitäten auf. Die A-Untereinheit bindet vorrangig an N-AcetylGalactosamin-Endgruppen, wohingegen die B-Untereinheit selektiv für terminale $\alpha-\delta$-Galactosyl-Endgruppen ist.

IB4 agglutiniert spezifisch mit Erythrozyten und wurde ursprünglich für diesen Zweck genutzt. Des Weiteren zeigten Studien, dass Isolektin IB4 zytotoxische Effekte auf körpereigene und Tumorzellen hat. Vor allem zeigte sich jedoch eine starke Affinität zu hirneigenen Mikrogliazellen und perivaskulären Zelltypen. Zusätzlich wird es in der Histochemie und Durchflusszytometrie zur Kennzeichnung endothelialer Zellen verschiedenster Spezies verwendet. IB4 wird zur Markierung (durch Injektion) von zentralen und peripheren neuronalen Signalwegen verwendet.

Für die vorliegende Studie müssen die Paraffinschnitte der Mikrogliazellen aus ZNS-Gewebe der Mäuse entparaffiniert werden. Hierfür wurden diese für 30 Minuten in Xylol gestellt und nachfolgend mittels einer absteigenden Alkoholreihe für 3 bis 5 Minuten behandelt. Der Alkohol wurde dann durch Spülung mit Aqua dest. entfernt und in Citratpuffer $(10 \mathrm{mmol} / \mathrm{l}, \mathrm{pH} 6.0)$ zur Antigendemaskierung für $5 \times 3$ Minuten in einer Mikrowelle bei $800 \mathrm{~W}$ gekocht. Um dem Austrocknen der Schnitte entgegenzuwirken, wurden diese nach jedem Kochvorgang abwechselnd mit Citratpuffer ( 0,1 molar) oder Aqua bidest. aufgefüllt. Im Anschluss erfolgten drei Waschungen in PBS und nachfolgend eine 10-minütige Inkubation in Wasserstoffperoxid-Lösung (3\% in PBS). Danach folgten erneute drei Waschungen in PBS. Im Anschluss daran wurden die Schnitte jeweils mit $100 \mu \mathrm{l}$ FCS-Lösung (10\% in PBS) bedeckt, für 30 Minuten in der feuchten Kammer inkubiert und mit $100 \mu \mathrm{l}$ Isolektin B4 $(5 \mu \mathrm{g} / \mathrm{ml}$, mit PBS verdünnt und mit 1\% BSA versetzt; Sigma, Taufkirchen, Germany) für 90 Minuten bei Raumtemperatur in der feuchten Kammer versetzt. Anschließend wurden die Schnitte drei mal in PBS gewaschen. Hiernach folgte die Zugabe von $100 \mu \mathrm{l}$ des Avidin-Biotin Komplexes (je 1:100 in PBS, ABC, Vector, Burlingame, CA) pro Schnitt und Inkubation für 45 Minuten in der feuchten Kammer. Nach erneut dreimaliger Waschung in PBS konnte die 
Visualisierung nach Eintreten der Farbreaktion mittels 5-minütiger Entwicklung unter dem Mikroskop mit DAB erfolgen. Nach abschließdender Aqua-dest.Spülung, 20-sekündigem „Bläuen“ in Hämalaun und erneutem Waschen mit Leitungswasser wurde die Färbung durch das Eindeckeln mit Immu-Dont auf einem Objektträger fertiggestellt. Im Ergebnis zeigen sich Braunfärbungen des Somas. Zur Färbung der Proben wurde das nachfolgende Protokoll verwendet (Tabelle 13).

\begin{tabular}{|c|c|c|}
\hline Schritt & Durchführung & Bemerkung \\
\hline Entparaffinieren & $\begin{array}{l}3 \times \text { Xylol-Bad für je } 10 \mathrm{Mi}- \\
\text { nuten } \\
\text { absteigende Alkoholreihe: } \\
2 \times 100 \% \text { Isopropanol } \Rightarrow \\
90 \% \text { Isopropanol } \Rightarrow 70 \% \\
\text { Isopropanol } \Rightarrow 50 \% \\
\text { Isopropanol } \Rightarrow \text { mit Aqua } \\
\text { destillata spülen }\end{array}$ & $\begin{array}{l}\text { die absteigende Alkohol- } \\
\text { reihe wurde jeweils } 3-5 \\
\text { Minuten durchgeführt }\end{array}$ \\
\hline Mikrowellenbehandlung & $\begin{array}{l}5 \times 3 \text { min á } 800 \mathrm{~W} \text { mit } \\
\text { Citratpuffer } \mathrm{pH}=610 \mathrm{mM} \\
\text { kochen }\end{array}$ & $\begin{array}{l}\text { dient der Demaskierung } \\
\text { der Eiweißstruktur }\end{array}$ \\
\hline Waschen & $3 \times 5 \mathrm{~min}$ in PBS & \\
\hline $\mathrm{H}_{2} \mathrm{O}_{2}$-Behandlung & $\begin{array}{l}3 \% \mathrm{H}_{2} \mathrm{O}_{2} \text { Behandlung } \\
\left(\mathrm{H}_{2} \mathrm{O}_{2}+\text { PBS }\right)\end{array}$ & $\begin{array}{l}\text { für } 10 \text { Minuten auf die } \\
\text { Schnitte geben }\end{array}$ \\
\hline Waschen & $3 x$ in PBS spülen & \\
\hline FCS-Behandlung & $\begin{array}{l}\text { 10\% FCS (Lösung mit PBS } \\
\text { ansetzen) }\end{array}$ & $\begin{array}{l}100 \mu l \text { pro Schnitt } \\
30 \text { Minuten auf dem Schnitt } \\
\text { bei RT belassen } \\
\text { anschließend nur abgie- } \\
\text { Ben, nicht spülen! }\end{array}$ \\
\hline Isolektin & $\begin{array}{l}\text { Isolektin in einer Ver- } \\
\text { dünnung von 1:40 auftra- } \\
\text { gen }\end{array}$ & $\begin{array}{l}100 \mu \mathrm{l} \text { pro Schnitt } \\
90 \text { Minuten auf dem Schnitt } \\
\text { bei RT belassen } \\
\text { Nach } 60 \text { Minuten Avidin- } \\
\text { Biotin-Komplex ansetzen. }\end{array}$ \\
\hline Waschen & $3 \times$ PBS & \\
\hline
\end{tabular}


Material und Methoden - Methoden

\begin{tabular}{|c|c|c|}
\hline Avidin-Biotin-Komplex & $98 \mu \mathrm{l} B S+1 \mu \mathrm{l} A+1 \mu \mathrm{l} B$ & $\begin{array}{l}\text { Lösung muss } 30 \text { Minuten } \\
\text { vorher stehen. } 100 \mu \text { l pro } \\
\text { Schnitt für } 45 \text { Minuten bei } \\
\text { RT einwirken lassen }\end{array}$ \\
\hline Waschen & $3 x$ PBS & \\
\hline DAB-Komplex & $\begin{array}{l}\text { 1:10 Verdünnung, (DAB- } \\
\text { Puffer, DAB-Komplex) }\end{array}$ & 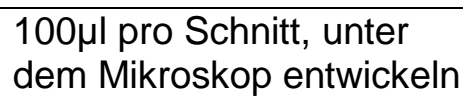 \\
\hline Waschen & Aqua destillata & \\
\hline Gegenfärbung & Mayers Hämalaun & $\begin{array}{l}\text { 20-30 Sekunden einwirken } \\
\text { lassen, anschließend in } \\
\text { Leitungswasser stellen }\end{array}$ \\
\hline Waschen & Leitungswasser & 10 Minuten „bläuen“ \\
\hline Eindeckeln & Immo-Dont & $\begin{array}{l}\text { Anschließend trocknen } \\
\text { lassen }\end{array}$ \\
\hline
\end{tabular}

Tabelle 13: Protokoll zur Färbung der Gehirnschnitte mit Isolektin B4 (IB4) 


\subsection{Versuchsaufbau}

Die Aufteilung der Tiere in der vorliegenden Studie wurde randomisiert in 2 Hauptgruppen vorgenommen. Die erste Gruppe (18Mo) sollte eine Zeit von maximal 18 Monaten überleben und die zweite Gruppe (14Mo) eine Zeit von maximal 14 Monaten. Beide Versuchsgruppen wurden nochmals in zwei weitere Gruppen mit gleicher Anzahl an Versuchstieren randomisiert: die Infektionsgruppe, die eine monatliche Infektion mit S. pneumoniae erhielt und die Kontrollgruppe, die eine monatliche Injektion mit $0.9 \% \mathrm{NaCl}$ erhielt (

Abbildung 3).

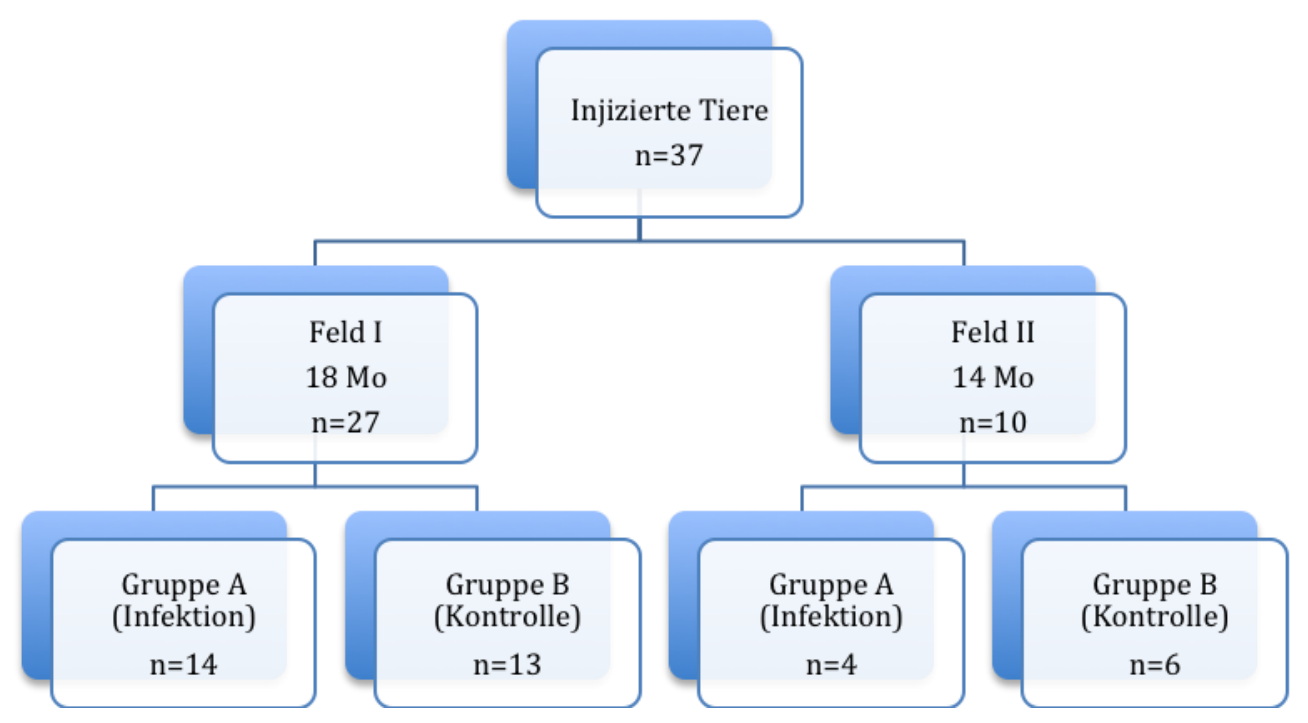

Abbildung 3: Versuchsaufbau mit Aufschlüsselung der einzelnen Arme

Im Anschluss an die Injektion erfolgte in allen Gruppen eine dreitägige antibiotische Behandlung mit einem Cephalosporin der 3. Generation. Für diese Studie wurde Ceftriaxon (Rocephin ${ }^{\circledR}$ ) der Firma Roche verwendet. Mit der antibiotischen Behandlung wurde 12h post infektionem begonnen. Während dieser Zeit verloren die mit S. pneumoniae infizierten Tiere bis zu 0,8 g ihres Gewichtes. Dieser Gewichtsverlust wurde als Reaktion auf die stattgefundene Infektion gewertet. Das Gewicht der Tiere wurde in der Anfangsphase, in der die Tiere gesund waren, 3 mal wöchentlich gemessen. Beim Auftreten der ersten pathologischen Anzeichen (klinischer Score=1) wurde das Gewicht alle 
1-2 Tage gemessen. In dem Zeitraum der Infektionen wurde jeden Tag das Gewicht dokumentiert.

So sollte gezeigt werden, wie sich der Einfluss einer Infektionen mit S. pneumoniae zu einem frühen (Feld I) und einem späteren Zeitpunkt (Feld II) auf die Maus und ihre Erkrankung an Morbus Parkinson auswirkt, und welcher Unterschied hinsichtlich des Erkrankungsbeginns, der Erkrankungsdauer und dem Schwerebild der Erkrankung zwischen den beiden Gruppen besteht. Außer dem Unterschied in der Überlebensdauer wurden alle Untersuchungen gleich durchgeführt.

Die Gruppe Feld I umfasste nach Anwendung der Ein- und Ausschlusskriterien ein Versuchstierkollektiv von 27 Mäusen, die Gruppe Feld II ein Kollektiv von 10 Mäusen.

Aus vorangegangenen Studien war bekannt, dass eine Maus, die mit S. pneumoniae infiziert wurde und den in dieser Studie notwendigen genetischen Code aufweist, jedoch keine Antibiose erhielt, nach spätestens $48 \mathrm{~h}$ an der Infektion verstarb (Nau und Eiffert 2002).

Die folgende Tabelle schlüsselt die einzelnen Infektionsarten der jeweiligen Tiere auf (Tabelle 14).

\begin{tabular}{|l|l|l|l|l|l|}
\hline Nummer & Infektion & Anzahl Infektion & Nummer & Infektion & Anzahl Infektion \\
\hline 4326 & Nein & 12 & 4389 & Ja & 6 \\
\hline 4327 & $\mathrm{Ja}$ & 12 & 4390 & $\mathrm{Ja}$ & 6 \\
\hline 4328 & $\mathrm{Ja}$ & 12 & 4391 & Nein & 12 \\
\hline 4329 & $\mathrm{Ja}$ & 12 & 4392 & Nein & 12 \\
\hline 4330 & $\mathrm{Ja}$ & 12 & 4393 & $\mathrm{Ja}$ & 12 \\
\hline 4331 & Nein & 12 & 4394 & $\mathrm{Ja}$ & 12 \\
\hline 4332 & Nein & 12 & 4395 & Ja & 12 \\
\hline 4333 & Nein & 12 & 4396 & Nein & 12 \\
\hline 4334 & Nein & 12 & 4397 & Nein & 12 \\
\hline
\end{tabular}


Material und Methoden - Versuchsaufbau

\begin{tabular}{|l|l|l|l|l|l|}
\hline 4335 & Nein & 12 & 4398 & Nein & 12 \\
\hline 4336 & Ja & 12 & 92 & Nein & 12 \\
\hline 4337 & Ja & 12 & 93 & Nein & 12 \\
\hline 4338 & Ja & 12 & 94 & Ja & 12 \\
\hline 4339 & Ja & 12 & 101 & Ja & 12 \\
\hline 4340 & Ja & 12 & 102 & Nein & 12 \\
\hline 4341 & Nein & 12 & 103 & Nein & 12 \\
\hline 4342 & Ja & 12 & 104 & Ja & 12 \\
\hline 4343 & Ja & 12 & 110 & Ja & 12 \\
\hline 4344 & Ja & 12 & 111 & Nein & 12 \\
\hline 4345 & Ja & 12 & 112 & Nein & 12 \\
\hline 4346 & Ja & 12 & & & \\
\hline 4347 & Ja & 12 & & & \\
\hline
\end{tabular}

Tabelle 14: Tiernummer mit Darstellung der Infektionsart und Anzahl der Infektionen 


\subsection{Statistik}

Die statistische Auswertung der einzelnen Parameter und graphischen Darstellungen wurden mit dem Programm GraphPad Prism Version 4.0 für Macintosh (GraphPad Software, San Diego, CA, USA) durchgeführt.

Parametrische Daten wurden mit dem Mittelwert $\%$ Standardabweichung, nicht parametrische Daten mit dem Median (25. Perzentil/ 75. Perzentil) ausgewertet.

Der Student t-Test wurde für den Vergleich zweier parametrischen Gruppen benutzt.

Der Mann-Whitney U-Test wurde für den Vergleich zweier nichtparametrischer Gruppen benutzt.

Das vor Beginn der Untersuchung gewählte Signifikanzniveau betrug $p<0,05$.

Die klinischen Scores, der Seiltest und der Rotarodtest wurde über die Zeit dargestellt. In den beiden Gruppen, der Infektionsgruppe und der Kontrollgruppe wurden die Area under the Curve (AUC) mit dem Mann-Whitney U-Test verglichen.

Die statistischen Analysen und graphischen Datenauswertung fand an einem MAC Power Book G4 unter dem Betriebssystem MacOS $^{\circledR}$ mit Hilfe von Standardprogrammen $\left(\right.$ Winword $^{\circledR}$, Excel ${ }^{\circledR}$, Graph Pad Prism ${ }^{\circledR}$ ) statt. 


\section{Ergebnisse}

Verstarb eine Maus der Infektionsgruppe entweder in der 14Mo oder in der 18Mo Versuchsreihe während der 3-tägigen Infektionszeit oder nach erfolgter Infektion, so wurde die Milz des Tieres herauspräpariert und auf einer Blutagarplatte kultiviert. Diese Untersuchung wurde als Nachweis der Todesursache durchgeführt, um sicher zu stellen, dass der Tod durch Infektion hervorgerufen wurde. Nach 1-2 Tagen konnten die auf der Blutagarplatte angezüchteten Streptokokken identifiziert werden.

Während des Versuches starben 5 Tiere im Laufe einer Infektion und wurden aus der Statistik ausgeschlossen.

\subsection{Einfluss rezidivierender systemischer Infektion mit Sp3 auf das}

\section{Gewicht}

Die mit S. pneumoniae infizierten Versuchtiere verloren während 3 Tage ab der Infektion bis zu 0,8g ihres Ausgangsgewichtes. Dieser Gewichtsverlust ist Folge der Infektion (Abbildung 4, Abbildung 5). Bei der Kontrollgruppe trat dieser Gewichtsverlust nicht auf.

Das Ausgangsgewicht aller Versuchstiere lag im Durchschnitt bei 27g. 


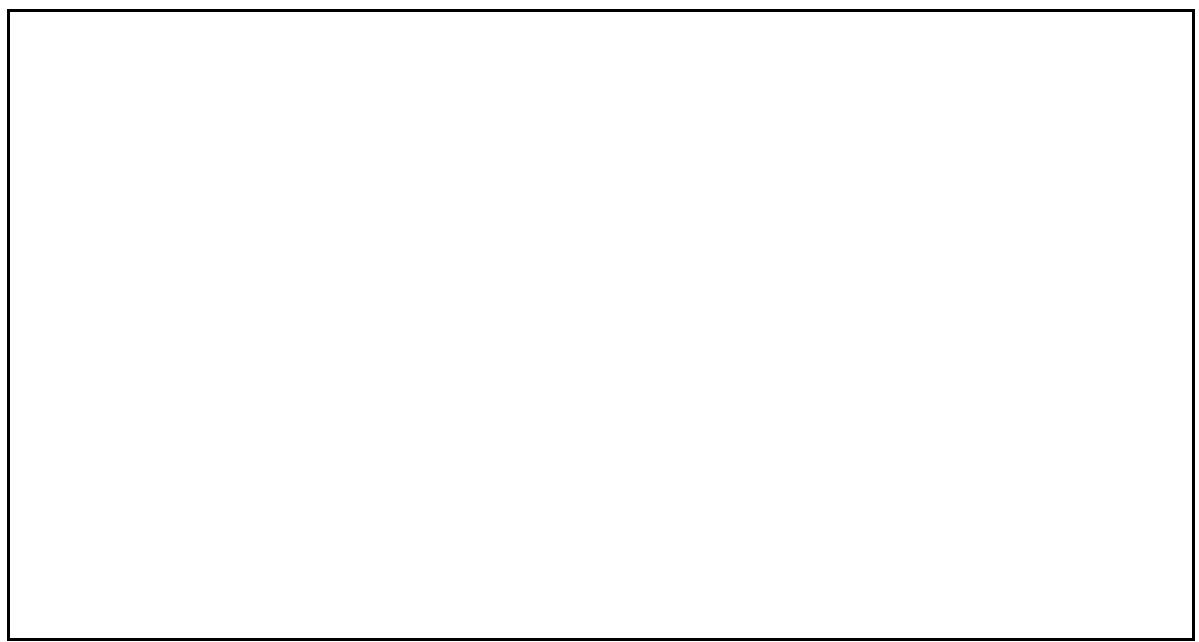

Abbildung 4: Verlauf des Gewichtes (g) im Kollektiv 14Mo. Infektionsgruppe (Infektion) $(n=4)$ vs. Kontrollgruppe (Kontrolle) $(n=6)$, gezeigt sind die Mediane beider Gruppen, die gegeneinander getestet wurden $(p=0,0023)$. Auf der Abszisse sind die Messungen an den einzelnen Tagen des Seiltestes zur übersichtlicheren Ansicht dargestellt.

Abbildung 5: Verlauf des Gewichtes (g) im Kollektiv 18Mo. Infektionsgruppe (Infektion, SP3) ( $n=14)$ vs. Kontrollgruppe (Kontrolle, $\mathrm{NaCl})(n=13)$, gezeigt sind die Mediane beider Gruppen, die gegeneinander getestet werden $(p=0,0011)$. 


\subsection{Einfluss rezidivierender systemischer Infektion mit Sp3 auf den klinischen Score}

Um den Krankheitszustand der Tiere beurteilen zu können, wurde der oben beschriebene Score gewählt (Tabelle 9), der einen Vergleich der Mäuse zulässt. Als klinischer Score wurde ein Zahlenwert zwischen 0-4 erhoben.

Alle Tiere, die im Alter von 2 Monaten das erste Mal mit S. pneumoniae $(n=4)$ infiziert wurden oder eine $\mathrm{NaCl}$-Injektion $(n=6)$ erhielten und im Alter von 14 Monaten (14Mo) getötet wurden, erreichten den klinischen Score 1. Aber keines der Tiere erreichte den Score 2 oder höher (Maximum-Score=1; Minimum-Score $=1$ ).

Alle Tiere, die nach 18 Monaten (18Mo) getötet und im Alter von 6 Monaten zum ersten Mal mit $\mathrm{S}$. pneumoniae infiziert wurden $(n=14)$ oder eine $\mathrm{NaCl}$ Injektion erhielten ( $n=10)$, erreichten den Score 1. In diesem Kollektiv erreichten zwei der Infektionsgruppe (Infektion mit S. pneumoniae) den Score 4 und eines der Kontrollgruppe (Kontrollgruppe, $\mathrm{NaCl}$ ) den Score 3 (Minimum-Score 1; Maximum-Score 4).

Der kumulative Score der infizierten Tiere des Kollekivs 14Mo, die im Alter von 2 Monaten die erste Infektion erhielten, betrug 90.0 (49.0/107.5). Der der Kontrollgruppe betrug 90.5 (45.5/112.5). Der Unterschied war mit $p=0,91$ statistisch nicht signifikant (Abbildung 6).

Der Verlauf der klinischer Score-versus-Zeit-Kurve der infizierten Tiere (Infektionsgruppe, Infektion) und Kontrolltiere (Kontrollgruppe, Kontrolle) des Kollektivs 14Mo, AUC (score $x$ days) 138,0 (81,00/170,0) versus 140,5 $(70,25 / 179,8)$ unterschied sich nicht signifikant mit $p=0,9143$. (Abbildung 7 ). 


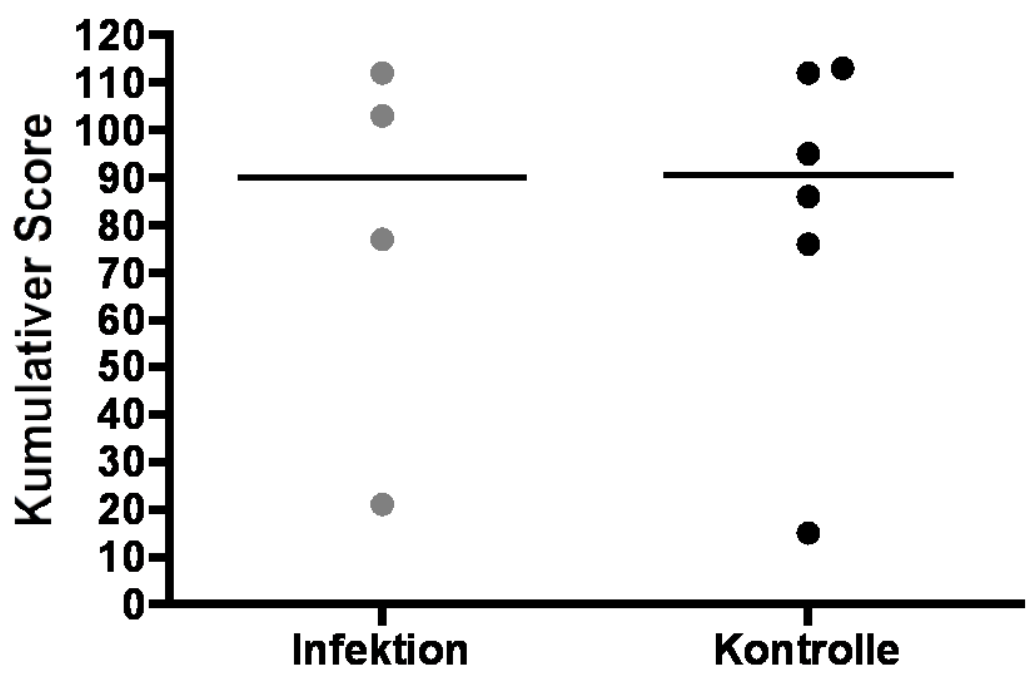

Abbildung 6: Kumulativer Score der A30P-Mäuse des Kollektivs 14Mo, Infektionsgruppe (Infektion) ( $n=4)$, Kontrollgruppe (Kontrolle) $(n=6), p=0,91$

Abbildung 7: Verlauf des klinischen Scores des Kollektivs 14Mo; Infektionsgruppe (Infektion) vs. Kontrollgruppe (Kontrolle), $(p=0,9143)$ 
Der kumulative Score der infizierten Tiere des Kollektivs 18Mo, die im Alter von 6 Monaten die erste Infektion erhielten betrug 69,50 (30,50/97,00), und der Kontrollgruppe $48,00(42,00 / 85,50)$ unterschied sich nicht signifikant mit $\mathrm{p}=$ 0,9806 (Abbildung 8).

Der Verlauf der klinischer Score-versus-Zeit-Kurve der infizierten Tiere (Infektionsgruppe, Infektion) und Kontrolltiere (Kontrollgruppe, Kontrolle) des Kollektivs 18Mo, AUC (score $x$ days) 151,5 (73,25/ 190,0) versus 123,5 (97,25/ 208,8), unterscheidet sich mit $p=0,6448$ statistisch nicht signifikant (Abbildung 9).

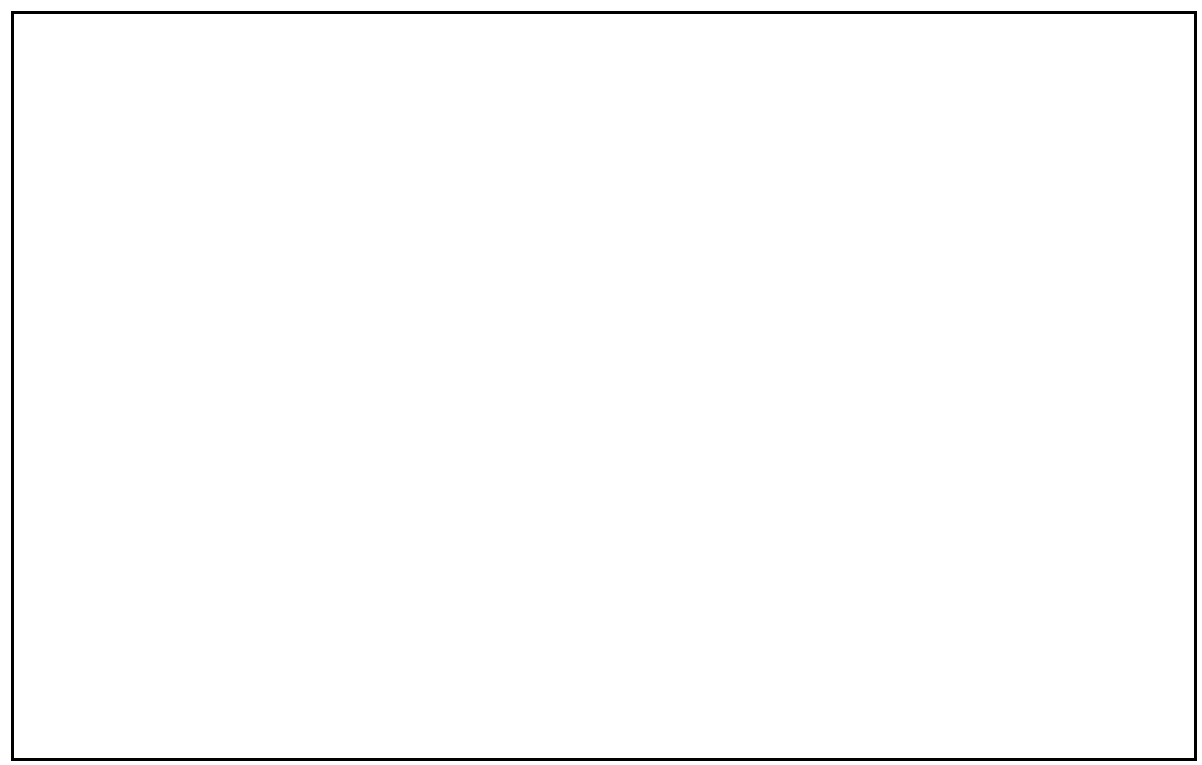

Abbildung 8: Kumulativer Score der A30P Mäuse des Kollektivs 18Mo Infektionsgruppe (Infektion) $(n=14)$, Kontrollgruppe (Kontrolle) $(\mathrm{N}=13),(\mathrm{p}=0,9806)$ 
Abbildung 9: Verlauf des klinischen Scores des Kollektivs 18Mo; Infektionsgruppe (Infektion, SP3) vs. Kontrollgruppe (Kontrolle), ( $p=0,6448)$ 
Das Alter der Tiere bis zum Erreichen vom Score 1 als Zeichen erster klinischer Symptome unterschied sich nicht (Abbildung 10).

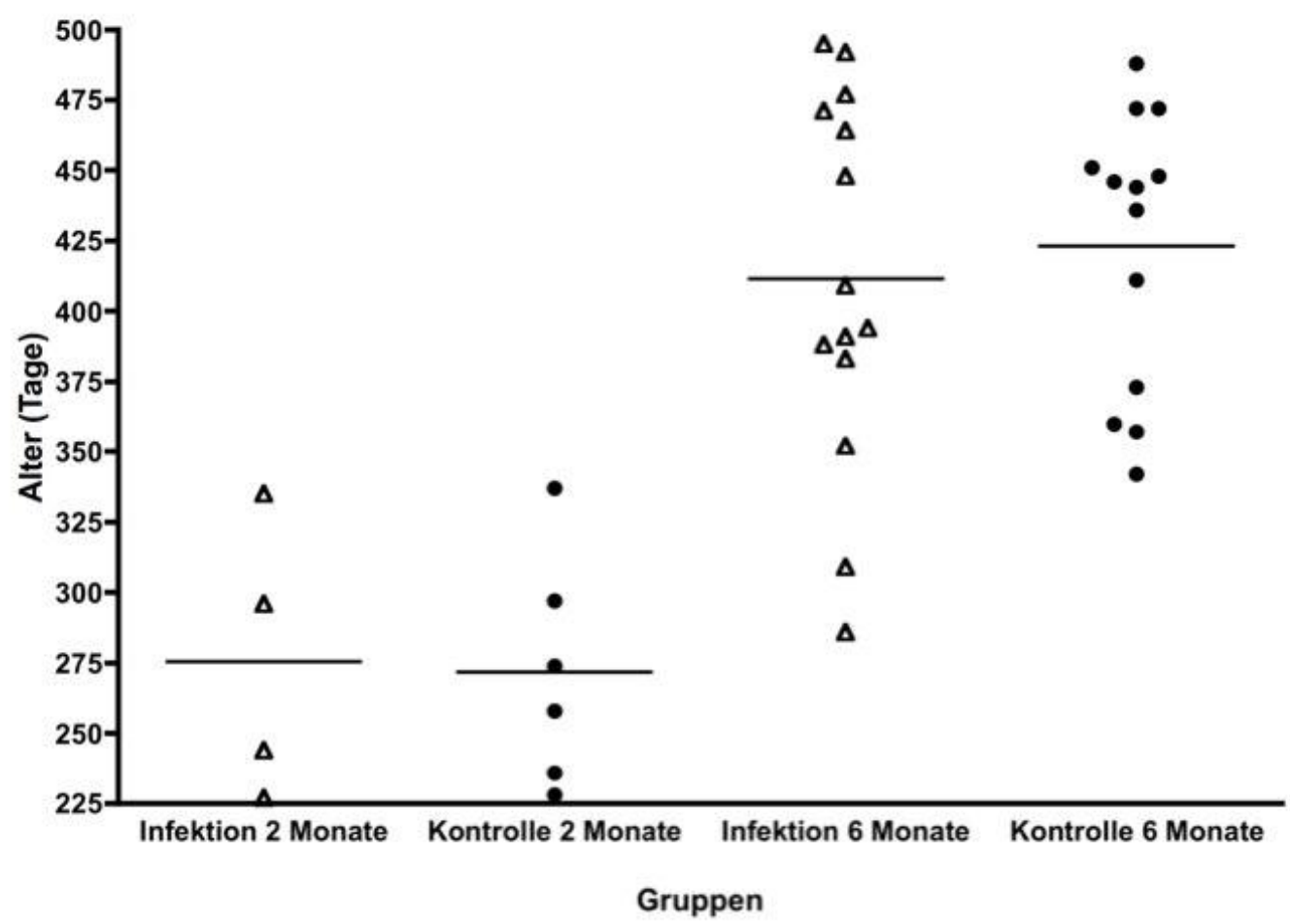

Abbildung 10: Alter der Tiere mit Injektionsbeginn im Alter von 2 Monaten (14Mo): Infektionsgruppe (Infektion) 270,0 (235,5/315,5) vs. Kontrollgruppe (Kontrolle) 266,0 $(232,0 / 317,0), p=0,8963$. Alter der Tiere mit Injektionsbeginn im Alter von 6 Monaten (18Mo): Infektionsgruppe (Infektion) 401,5 (367,5/474,0) vs. Kontrollgruppe (Kontrolle) $444,0(366,5 / 461,5),(p=0,6092)$ 


\subsection{Einfluss rezidivierender systemischer Infektion mit Sp3 auf den Rotarod-Test}

Die Untersuchung der motorischen und koordinativen Fähigkeiten mittels Rotarod-Test zeigte im Laufe des Experimentes keinen Unterschied zwischen den infizierten Tieren und den Kontrolltieren.

Die Auswertung der Tiere, die mit 2 Monaten das erste Mal eine Injektion erhielten, stellte sich folgendermassen dar: AUC (seconds $x$ days) Infektionsgruppe (Infektion, SP3) 59793.0 (54297.0/65693.0) vs. Kontrollgruppe (Kontrolle, $\mathrm{NaCl}$ ) 54417.0 (53551.0/62550.0), ( $p=0.35$ ) (Abbildung 11).

Abbildung 11: Verlauf des Rotarod-Testes des Kollektivs 14Mo; Infektionsgruppe (Infektion) ( $n=4)$ vs. Kontrollgruppe (Kontrolle) $(n=6),(p=0,35)$. Gezeigt sind die Mediane mit der 25. und 75. Perzentile

Die Auswertung der Tiere, die mit 6 Monaten das erste Mal eine Injektion erhielten, stellt sich folgendermassen dar: AUC (seconds $\mathrm{x}$ days) Infektionsgruppe (Infektion, SP3) $85354.0 \quad(78498.0 / 101924.0) \quad$ vs. 
Kontrollgruppe (Kontrolle, $\mathrm{NaCl}) \quad 82731.0 \quad(76286.0 / 97932.0), \quad p=0.344$ (Abbildung 12).

Abbildung 12: Verlauf des Rotarod-Testes des Kollektivs 18Mo; Infektionsgruppe (Infektion, SP3) ( $n=14)$ vs. Kontrollgruppe (Kontrolle, NaCl) $(n=13),(p=0,344)$. Gezeigt sind die Mediane mit dem 25. und 75. Perzentil

Fazit: Die motorischen Leistungen im Rotarod-Test zeigten keinen signifikanten Unterschied mit $p=0,344$ bzw. $p=0,35$. 


\subsection{Einfluss rezidivierender systemischer Infektion mit Sp3 auf den}

\section{Seiltest}

Alle Tiere, die im Alter von 2 Monaten die erste Injektion erhielten, Infektionsgruppe (SP3) $(n=4)$ vs. Kontrollgruppe $(0,9 \% \mathrm{NaCl})(n=6)$, zeigten im Seiltest eine stabile Leistung über die gesamte Versuchzeit hinweg. AUC (score $x$ days) Infektionsgruppe (SP3) 1179.0 (947.0/1372.0) vs. Kontrollgruppe (0,9\% $\mathrm{NaCl}) 1108.0$ (1067.0/1427.0), $\mathrm{p}=0,7619$ (Abbildung 13).

Abbildung 13: Verlauf des Seiltestes des Kollektivs 14Mo; Infektionsgruppe (SP3) $(n=4)$ vs. Kontrollgruppe $(0,9 \% \mathrm{NaCl})(n=6)$, gezeigt sind die Mediane mit der 25 . und 75. Perzentil $(p=0,7619)$

Alle Tiere, die im Alter von 6 Monaten die erste Injektion erhielten, Infektionsgruppe (SP3) ( $n=14)$ vs. Kontrollgruppe $(0,9 \% \mathrm{NaCl})(n=13)$, zeigten im Seiltest eine stabile Leistung über die gesamte Versuchzeit hinweg. AUC (score $x$ days) Infektionsgruppe (SP3) 1055.0 (926.0/1123.0) vs. Kontrollgruppe $(0,9 \% \mathrm{NaCl}) 1140.0$ (909.0/1323.0), $\mathrm{p}=0,2750$ (Abbildung 14). 


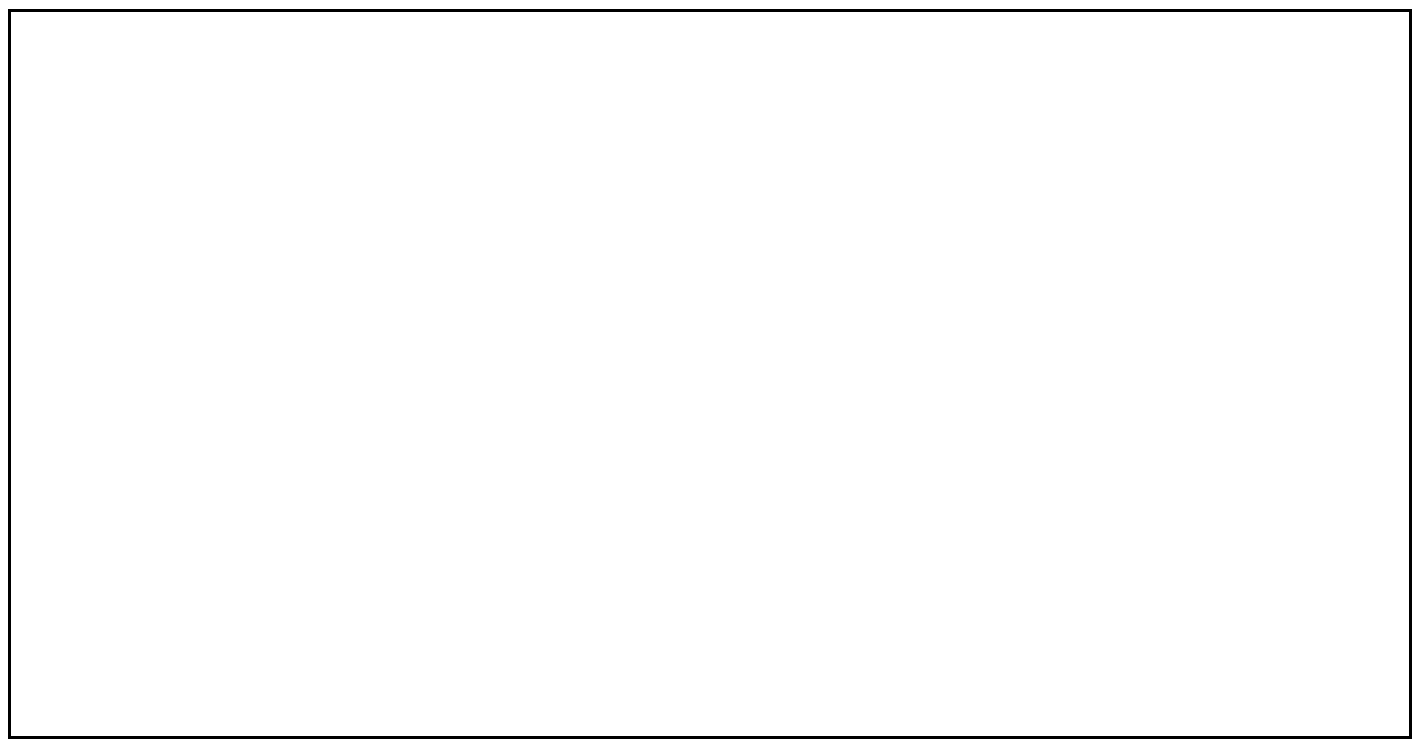

Abbildung 14: Verlauf des Seiltestes des Kollektivs 18Mo; Infektionsgruppe (SP3) $(n=14)$ vs. Kontrollgruppe $(0,9 \% \mathrm{NaCl})(n=13)$, gezeigt sind die Mediane mit der 25. und 75. Perzentil $(p=0,2750)$

Fazit: Im Vergleich zeigte sich zwischen der Infektionsgruppe und der Kontrollgruppe kein signifikanter Unterschied über die gesamte Beobachtungszeit mit $p=0,719$ bzw. $p=0,275$.

\section{5. Überlebenszeit}

Das Alter der Mäuse zum Todeszeitpunkt war in beiden Gruppe ohne Unterschied. (Abbildung 15).

Abbildung 15: Alter in beiden Gruppen zum Todeszeitpunkt 


\subsection{Histologische Auswertung}

\subsubsection{Hämatoxylin-Eosin (HE)- Färbung}

Durch die HE-Färbung werden die Zellkerne blau und die zytoplasmatischen Bestandteile rosa bis rot dargestellt.

Als Vergrößerung wurden eine Übersichtsaufnahme mit 4x0.13-fach und eine Detailaufnahme mit 40x0.75-fach angefertigt.

In den Aufnahmen erkennt man beim Vergleich einzelner Strukturen keine Unterschiede zwischen den einzelnen Gruppen (Abbildung 16).
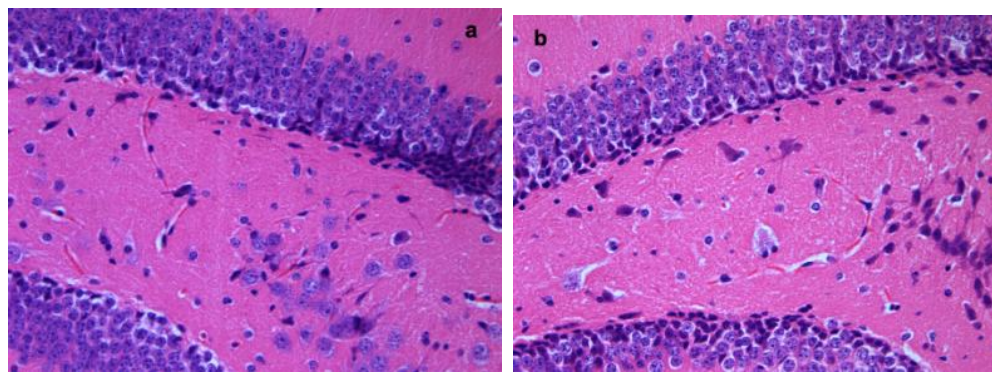

Abbildung 16: Färbung von Hirnschnitten Gyrus dentatus mittels Hämatoxylin-Eosin (HE), Vergleich der Strukturen ohne (a) und mit (b) Infektion durch S. pneumoniae

\subsubsection{Isolektin-B4 (IB4)- Färbung}

Die Anfärbung der Mikrogliazellen zeigte bezüglich der Anzahl und Aktivierung in beiden Gruppen keinen Unterschied (Abbildung 17).
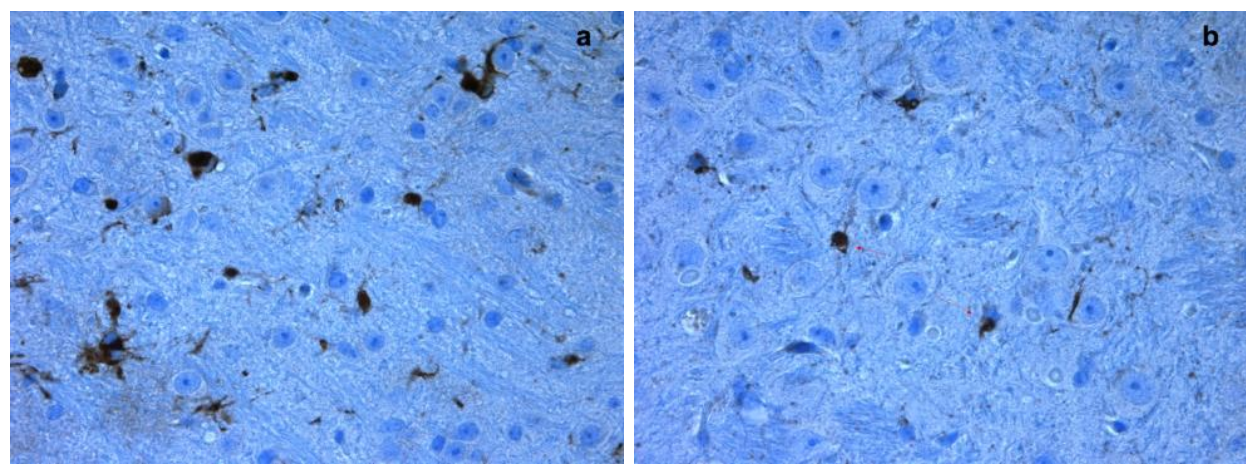

Abbildung 17: Färbung von Hirnschnitten mittels Isolectin B4, Vergleich von Hirnschnitten Gyrus dentatus ohne (a) und mit (b) Infektion durch S. pneumoniae. 


\subsubsection{Alpha-Synuclein-Überproduktion}

Der Gehalt an $\alpha$-Synuclein wurde mittels ELISA bestimmt. Der $\alpha$ Synucleingehalt im Gehirn von A30P Mäusen, die Infektionen mit S. pneumoniae im Alter von 6 Monaten erhalten hatten und im Alter von 18 Monaten getötet wurden $(1384.0 \% 341.8 \mathrm{pg} / \mathrm{ml})$, unterschied sich nicht von dem im Gehirn von A30P-Mäusen, die Injektionen mit $\mathrm{NaCl}$ erhalten hatten $(1403.0 \% 376.0 \mathrm{pg} / \mathrm{ml}, \mathrm{p}=0.90)$. Dagegen unterschieden sich beide Gruppen der A30P Mäuse deutlich von den WT-Mäusen, die keine Injektion erhielten, bezüglich des $\alpha$-Synuclein-Gehaltes (398.0 $\% 67.3 \mathrm{pg} / \mathrm{ml}, \mathrm{p}=<0.001)$ (Abbildung 18).

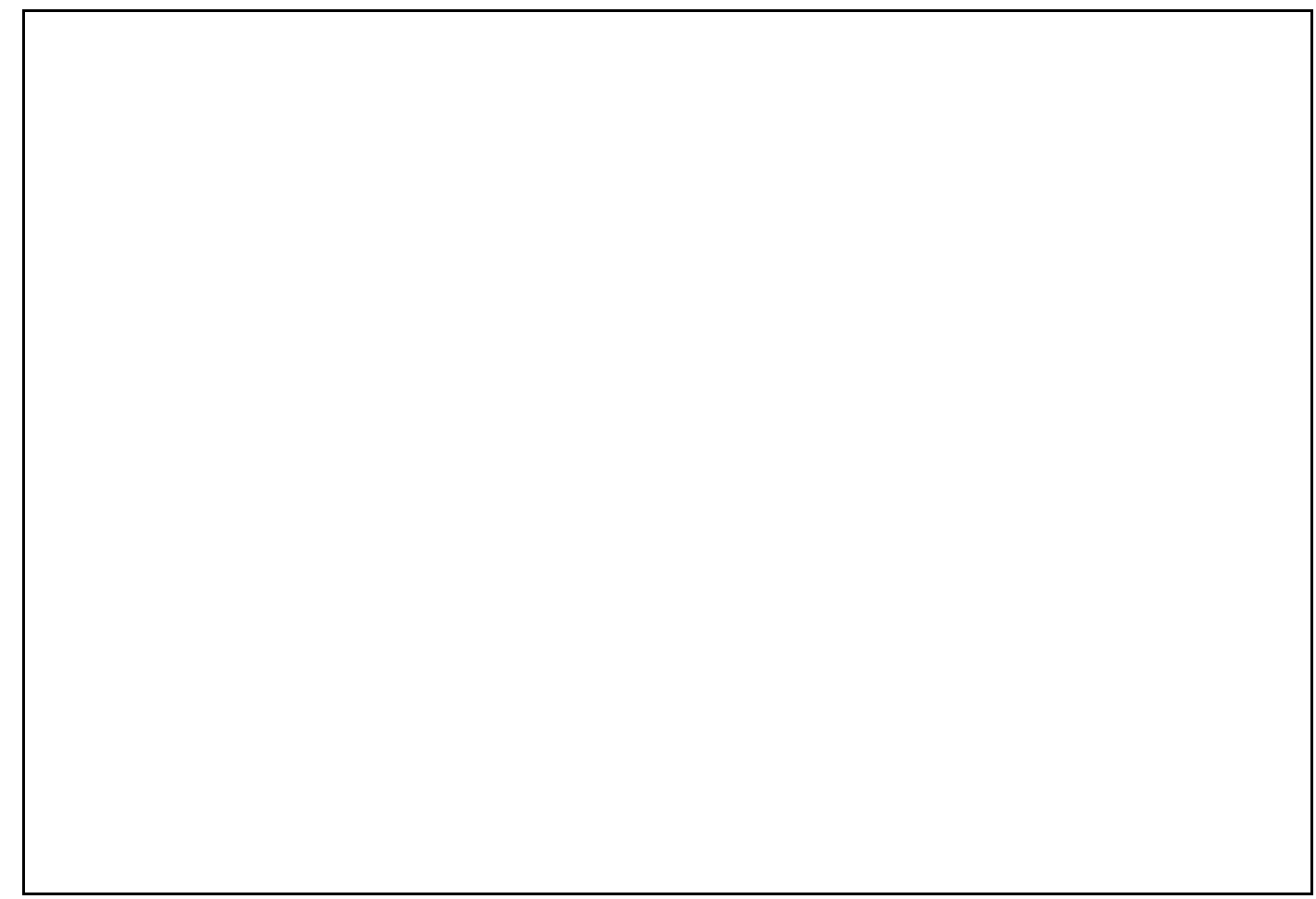

Abbildung 18: Mittelwerte von intrazerebralem Gehalt an -Synuclein bei A30P Mäusen mit Infektion durch S. pneumoniae (Infektionsgruppe, Infektion, $n=12$ ) und ohne Infektion (Kontrollgruppe, Kontrolle, $n=11$ ) vs. Wildtyp-Mäuse $(W T, n=3$ ) 


\section{Diskussion}

Die fortschreitende Verschlechterung bei neurodegenerativen Erkrankungen (wie IPS, AD und ALS) im Rahmen von systemischen Infektionen ist ein häufig beobachtetes klinisches Phänomen. Patienten mit neurologischen Erkankungen leiden, wie bereits in der Einleitung beschrieben, häufig unter systemischen Infektionen wie akuten Harnwegs- und pulmonalen Infektionen (Murray et al. 1993; Elie et al. 1998; Albert et al. 1999; Gelanis 2001; Holmes et al. 2003). Bisher wurde dieser Zusammenhang zwischen neurodegenerativen Erkrankungen und systemischer Infektion trotz deutlich steigendem Interesse noch nicht genauer, auch nicht im Tiermodell, untersucht. In dieser Arbeit wurden die Auswirkungen von systemischen Infektionen mit S. pneumoniae als hauptverantwortlichem pathogenen Keim für Atemwegsinfekte beim Erwachsenen auf den Beginn und Verlauf des Morbus Parkinson im Mausmodell untersucht. In parallel laufenden Studien wurde der gleiche experimentelle Ansatz im Mausmodell des Morbus Alzheimer und der Amyotrophen Lateralsklerose durchgeführt.

In der vorliegenden Studie war der Beginn (erste klinische Symptome nach ca. 14 Monaten) und der Verlauf der Parkinsonerkrankung in A30P Mäusen vergleichbar mit bereits vorliegenden Studien (Freichel et al. 2007). Chronische systemische Infektion (Injektion mit S. pneumoniae) gelten als potenter infammatorischer Stimulus, um die Krankheitsprogression zu beeinflussen. In der vorliegenden Arbeit wurde weder der Krankheitsbeginn noch der Krankheitsverlauf durch die systemische Infektion beeinflusst. Die Mikrogliazellen waren durch ILB4 histologisch zu verifizieren, jedoch unterschied sich weder die Anzahl noch der Aktivitätsgrad zwischen infizierten Tieren und Kontrolltieren. Zusätzliche Aktivierung der Mikrogliazellen hätte ein akutes Geschehen im Rahmen der akuten systemischen Infektion verdeutlichen können. Die Tiere in diesen Studien wurden nach 14 bzw. 18 Monaten getötet, so dass auch ein längeres Zeitintervall beobachtet werden konnte. Auf Grund des schleichenden Verlaufs der Erkrankung konnte in der vorliegenden Studie 
die Auswirkung einer systemischen Infektion über einen längeren Zeitraum, bis maximal 18 Monate, sowie auch die sehr frühen Veränderungen beobachtet und dokumentiert werden. Godoy zeigte 2008 in einem Tierexperiment (Ratten6-Hydroxydopamin-Modell), dass zentrale LPS Injektionen in die Substantia nigra neurodegenerative Erkrankungen verschlechtern und vor allem die motorischen Defizite schneller voranschreiten lassen (Godoy et al. 2008). Der Einfluss einer systemischen Infektion wurde bisher nicht genauer untersucht. In der vorliegenden Studie zeigte sich jedoch, dass es keinen signifikanten Unterschied zwischen den infizierten und gesunden Tieren hinsichtlich der Koordination und Motorik (Seiltest, Rotarod-Test) oder bezüglich des Krankheitszustandes (Klinischer Score) gab. Der Gewichtsverlauf in beiden Gruppen unterschied sich mit 0,8kg Verlust bei den erkrankten Tieren ebenfalls kaum. Vor allem das Ergebnis, dass mehr Tiere der Kontrollgruppe einen höheren Krankheitsscore erreichten als solche der infizierten Gruppe, spricht gegen eine Verschlechterung der Erkrankung durch rezidivierende systemische Infektion mit S. pneumoniae in diesem Modell.

Alpha-Synuclein wird in Zusammenhang mit aktivierten Microgliazellen in Gehirngewebe von PD-Patienten gebracht (Croisier et al. 2005; Zhang et al. 2005). In vitro konnten Klegeris et al. 2008 nachweisen, dass Alpha-Synuclein Microglia-vermittelte Neurotoxizität in mutierten A30P Mäusen beeinflusst. Der Alpha-Synuclein Gehalt im Gehirngewebe von A30P-Mäusen, die in der vorliegende Studie verwendet wurden, war ca. dreimal höher als in Wild-TypMäusen. Im Vergleich zwischen infizierten Mäusen und Kontrollgruppe unterschied sich weder der Gehalt an Alpha-Synuklein noch die Anzahl an aktivierten Microglia-Zellen.

Im Vergleich zu den Studien durch Nguyen et al. und Cunningham et al. sind die hier erhobenen Daten eher überraschend (Nguyen et al. 2004; Cunningham et al. 2005). In Relation zum Plasmaendotoxinlevel im Picogrammniveau bei Patienten, die an einer Sepsis litten, sind die bei Nguyen und Cunningham verwendeten Dosen von LPS sehr hoch angelegt (Kojika et al. 2006). In-vitroDaten deuten an, dass die durch Mikrogliastimulation hervorgerufen Effekte 
(Neurotoxizität oder Neuroprotektion) von der Höhe des infektiösen Stimulans abhängen (Lu et al. 2007). Der in der vorliegenden Studie genutze infektiöse Stimulus ist im Vergleich zu Nguyen und Cunningham eher gering, jedoch ohne Antibiotikagabe trotzdem letal für die Mäuse (Nau und Eiffert 2002).

Alpha-Synuclein sensibilisiert die dopaminergen Neurone gegenüber oxidativem Stress und erhöht die Bildung freier Radikale (Westrich 2008). Somit scheint es sinnvoll, den weiteren Zusammenhang zwischen oxidativem Stress, Alpha-Synuclein und dem Beginn der Parkinson-Erkrankung sowie auch dessen Verlauf zur weiteren Vertiefung des Pathomechanismus der Parkinsonerkrankung zu beleuchten.

Alternative Forschungsansätze könnten in der herkömmlichen Therapie von hochdosiertem Kortison liegen. Sowohl im akuten Schub bei Multipler Sklerose (MS) als auch bei Parkinson-Kranken lässt sich die Beschwerdesymptomatik durch hochdosierte Kortisongabe zumindest zeitweilig lindern. Fraglich ist in diesem Zusammenhang sicherlich der mögliche Einfluss auf die AlphaSynucleinerhöhung.

In Bezug auf die Blut-Hirn-Schranke ist man bis zu Beginn des 21. Jahrhunderts davon ausgegangen, dass neurodegenerative Erkrankungen, wie die Alzheimer- und die in dieser Studie näher untersuchte Parkinson-Krankheit, keinen Einfluss auf die Blut-Hirn-Schranke haben. Neuere Untersuchungsergebnisse widerlegen diese These. Mit Hilfe der kontrastmittelverstärkten Magnetresonanztomographie und biochemischer Untersuchungen des Liquors konnten beispielsweise bei Alzheimer-Patienten im Vergleich zu einer Gruppe gleichaltriger nicht erkrankter Personen funktionale Veränderungen der Blut-Hirn-Schranke in Richtung einer erhöhten Durchlässigkeit festgestellt werden (Farrall und JM 2009). Die erhöhte Permeabilität ist offensichtlich schon bei einem sehr frühen Stadium der Erkrankung vorhanden (Starr 2009). Die Konsequenzen dieser Erkenntnisse werden derzeit noch kontrovers diskutiert (Zlokovic 2005). Die Veränderungen an der Blut-Hirn-Schranke könnten Einfluss auf die Progression der 
Diskussion

Erkrankung, sowie auf mögliche zukünftige Therapieansätze haben (Desai 2007). 


\section{Zusammenfassung}

Neurodegenerative Erkrankungen verschlechtern sich häufig im Rahmen einer akuten Infektion, z.B. durch das Bakterium Streptococcus pneumoniae (Harnwegs- und obere Atemwegsinfekte). Um bessere Therapieansätze zu erhalten und die pathomechanischen Zusammenhänge zu verstehen, wurde an transgenen Mäusen mit der Mutation (THY1)-A30PaSYN der Einfluss einer rezidivierenden systemischen Infektion mit einem häufig vorkommenden respiratorisch-pathogenen Keim, Streptococcus pneumoniae, untersucht. Die Mäuse wurden wiederholt mit $\mathrm{S}$. pneumoniae intraperitoneal infiziert und mit Ceftriaxon ${ }^{\circledR}$ behandelt. Die infizierten Tiere sowie die Kontrollgruppe wurden mittels dreier unterschiedlicher Testversionen überprüft: Seiltest, klinischer Score und Rotarod-Test. Im Alter von 14 bzw. 18 Monaten wurden die Mäuse mittels Genickbruch getötet, so dass das Gehirn untersucht werden konnte. Dafür wurde der durch Mollenhauer et al. entwickelte ELISA genutzt. In Zusammenschau der durchgeführten Experimente und Testverfahren lässt sich abschließend feststellen, dass die wiederholte systemische Infektion mit S. pnemoniae, in dieser Studie, keine Auswirkung auf den Beginn oder den Verlauf der Parkinson-Erkrankung hat. Die Beobachtungszeit von bis zu 14 und 18 Monaten ergab keine signifikanten Unterschiede. Die Diagnose der ersten klinischen Symptome des Morbus Parkinson war in beiden untersuchten Gruppen, 14 bzw. 18 Monaten, ebenfalls nicht unterschiedlich.

Zusammenfassend lässt sich sagen, dass die durch S. pneumoniae ausgelöste moderate bis schwere Infektion keinen signifikanten Einfluss auf den Beginn oder Verlauf der in dieser Arbeit untersuchten neurodegenerativen Krankheit Morbus Parkinson hat. 


\section{Literaturverzeichnis}

Albert S, Costa R, Mechant C, Small S, Jenders R, Stern Y (1999): Hospitalization and ALzheimer's disease: results from a community-based study. J Gerontol A Biol Sci Med Sci $\underline{54}$, 267-271

Aloisi F (2001): Immune function of microglia. Glia $\underline{36}, 165-179$

Bailey K, Rustay N, Crawley J (2006): Behavioral Phenotyping of Transgenic and Knockout Mice: Practical Concerns and Potential Pitfalls. ILAR J 47(2), 124-131

Barrientos R, Higgins E, Biedenkapp J, Sprunger D, Wright-Hardesty K, Watkins $L$ (2006): Peripheral infection and aging interact to impair hippocampal memory consolidation. Neurobiol Aging 27, 723-732

Beal M (2001): Experimental models of Parkinson's disease. Nat Rev Neurosci 2, 325-334

Berlit P: Klinische Neurologie, 2. Auflage; Springer, Berlin 2005

Bernheimer H, Birkenmayer W, Hornykiewicz O, Jellinger K, Seitelberger F (1973): Brain dopamine and the syndromes of Parkinson and Huntignton. Clinical, morphological and neurochemical correlations. J Neurol Sci $\underline{20}$, 415455

Betabert R, Sherer T, Greenamyre J (2002): Animal models of Parkinson's diseases. Bioessays $\underline{24}, 308-318$

Caston J, Lalonde R, Delhaye-Bouchaud N, Mariani J (1998): The cerebellum and postural sensorimotor learning in mice and rats. Behav Brain Res 95 (1), 17-22

Clayton D, George J (1998): The synucleins: a family of proteins involved in synaptic function, plasticity, neurodegeneration and disease. Trends Neurosci 21(6), 249-254 
Clayton DF, George JM (1999): Synuclein in synaptic plasticity and

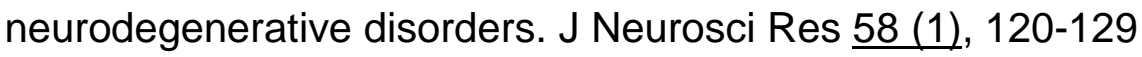

Combrinck M, Perry V, Cunningham C (2002): Peripheral infection evokes exaggerated sickness behavious in pre-clinical murine prion disease. Neuroscience $\underline{112}, 7-11$

Conway K, Rochet J, Bieganski R, Lansbury PJ (2001): Kinetic stabilization of the alpha-synuclein protofibril by a dopamine-alpha-synuclein adduct. Science $\underline{294}, 6-9$

Cookson M (2005): The biochemistry of Parkinson's disease. Annu Rev Biochem $\underline{74}, 29-52$

Croisier E, Moran LB, Dexter DT, Pearce RK, Graeber MB (2005): Microglial inflammation in the parkinsonian substantia nigra: relationship to alphasynuclein deposition. J Neuroinflammation $\underline{3}, 2-14$

Cunningham C, Wilcockson D, Campion S, Lunnon K, Perry V (2005): Central and systemic endotoxin challenges exacerbate the local inflammatory response and increase neuronal death during chronic neurodegeneration. J Neurosci $\underline{25(40)}, 9275-9284$

Cunningham C, Campion S, Lunnon K, Murray C, Woods J, Deacon R (2009): Systemic inflammation induces acute behavioral and cognitive changes and accelerates neurodegenerative disease. Biol Psychiatry $\underline{65(4)}$ 304-312

Davidson W, Jonas A, Clayton D, George, J (1998): Stabilization of alphasynuclein secondary structure upon binding to synthetic membranes. J Biol Chem 273, 9443-9449

Dawson T, Mandir A, Lee M (2002): Animal models of PD: pieces of the same puzzle? Neuron $\underline{35}, 219-222$

Desai B (2007): Blood-brain barrier pathology in Alzheimer's and Parkinson's disease: implications for drug therapy. Cell Transplant 16, 285-299 
Dexter D, Carayon A, Vidailhet M, Ruberg M, Agid F, Agid Y (1990): Decreased ferritin levels in brain in Parkinson's disease. J Neurochem 55(1), 16-20

Dluzen D, McDermott J (2000): Gender differences in neurotoxicity of the nigrostrial dopaminergic system: implications for Parkinson's disease. J Gend Specif Med $\underline{3}, 36-42$

Duda J, Giasson B, Mabon M, Miller D, Golbe L, Lee VY (2002): Concurrence of alpha-synuclein and tau pathology in a Contursi kindred brain. Acta Neuropathol 104(1), 7-11

Duffy P, Menefee M (1965): Electron microscopic observations of neurosecretory granules, nerve and glial fibers, and blood vessels in the median eminence of the rabbit. Am J Anat 117(2), 251-286

Ebert S, Gerber J, Bader S, Mühlhauser F, Brechtel K, Mitchell T (2005): Dosedependetn activation of microglial cells by Toll-like receptor agonists alone and in combination. J Neuroimmunol $\underline{159}, 87-96$

Elie M, Cole M, Primeau F, Bellavance F (1998): Delirium risk factor in elderly hospitalized patients. J Gen Intern Med 13, 294-312

Engvall E, Perlmann P: Enzyme linked immunosorbent assay (ELISA). Quantitative assay of immunoglobulin G. Immunochemistry $\underline{\text { 8(9) }}$, 871-874

Farrall A, JM W (2009): Blood-brain barrier: Ageing and microvascular disease systematic review and meta-analysis. Neurobiol Aging 30, 337-352

Farrer M, Kachergus J, Forno L, Lincoln S, Wang D, Hulihan M (2004): Comparison of kindreds with parkinsondism and alpha-synuclein genomic mulitplications. Ann Neurol 55(2), 174-179

Fearnley J, Lees A (1991): Aging and Parkinson's disease: substantia nigra regional selectivity. Brain 114(5), 2283-2301 
Forno L, DeLanney L, Irwin I, Langston J (1995): Ultrastructure of eosinophilic inclusion bodies in the amygdala-parahippocampal of aged squirrel monkeys treated with 1-methyl-4-phenyl-1,2,3,6-tetrahydropyridine, a dopaminergic neurotoxin. Neurosci Lett $\underline{184}, 44-47$

Frasier M, Walzer M, McCarthy K, Magnuson D, Lee J, Haas C (2005): Tau phosphorylation increases in symptomatic mice overespressing A30P alphasynuclein. Exp Neurol 192, 274-287

Freichel C, Neumann M, Ballard T, Müller V, Woolley M, Ozmen L, Borroni E, Kretzschmar HA, Haass C, Spooren W, Kahle PJ (2007): Age dependent cognitive descline and amygdala pathology in alpha-synuclein transgenic mice. Neurobiol Aging $\underline{28}$, 1421-1435

Gelanis D (2001): Respiratory failure or impairment in amyotrophic lateral sclerosis. Curr Treat Options Neurol $\underline{3}, 133-138$

Godoy MCP, Tarelli R, Ferrari CC, Sarchi MI, Pitossi J (2008): Central and systemic IL-1 exacerbates neurodegeneration and motor symptoms in a model of Parkinson's disease. Brain 131, 1880-1894

Goldsby R, Kindt T, Osborne B, Kuby J: Enzyme linked immonosorbent assay; in: Immunology, 5. Auflage; WH Freeman, New York 2003, 148-150

Hall M (1841): On the Diseases and Derangements of the Nervous System. London. H Baillière 320-321

Hermann I, Kellert M, Schmidt H, Mildner A, Hanisch U, Brück W (2006): Streptococcus pneumoniae infection aggravates experimental autoimmune encephalomyelitis via Toll-like receptor 2. Infect Immun $\underline{74}$, 4841-4848

Holmes C, El-OkI M, Williams A, Cunningham C, Wilcockson D, Perry V (2003): Systemic infection, interleukin-1-beta, and cognitive decline in Alzheimer's disease. J Neurol Neurosurg Psychiatry $\underline{74}, 788-789$

Ilev A, Stringaris A, Nau R, Neumann H (2004): Neuronal injury mediated via stimulation of microglial Toll-loke receptor-9 (TLR9). FASEB J $\underline{18}, 412-414$ 
Iwai A, Yoshimoto M, Masliah E, Saitoh T (1995): The precursor protein of on-A neta compoent of Alzheimer's disease amyloid is a presynaptic protein of the central nervous system. Neuron $\underline{14}, 467-475$

Javitch J, D'Amato R, Strittmatter S, Snyder S (1985): Parkinsonism-inducing neurotoxin, N-methyl-4-phenyl-1,2,3,6 -tetrahydropyridine: uptake of the metabolite $\mathrm{N}$-methyl-4-phenylpyridine by dopamine neurons explains selective toxicity. Proc Natl Acad Sci 82(7), 2173-2177

Jellinger K, Kienzl E, Rumpelmair G, Riederer P, Stachelberger H, BenShachar D (1993): Neuromelanin and nigrostriatal dopamine neuron degeneration. J Neurochem 60(5), 1976-1977

Jenco J, Rawlingson A, Daniels B, Morris A (1998): Regulation of Phospholipase D2: selective inhibition of mammalian phospholipase $D$ isoenzymes by alpha- and beta-synucleins. Biochemistry $\underline{37}$, 4901-4909

Kahle P, Haass C (2004): How does Parkin ligate ubiquitin to Parkinson's disease? EMBO R $\underline{5}, 681-685$

Kahle P, Neumann M, Ozmen L, Müller V, Jacobsen H, Schinzielorz A (2000): Subcellular localisation of wild-type and parkinson' disease-assoviated mutant alpha-synuclein in human an transgenic mouse brain. J Neurosci $\underline{20}$, 63656373

Kahle P, Neumann M, Ozmen L, Müller V, Odoy S, Okamoto N (2001): Selective insolubility of alpha-synuclein in human Lewy body diseases is recapitulated in a transgenic mouse model. Am J Pathol 159, 2215-2225

Kim T, Paik S, Yang C (2002): Structural and functional implications of Cterminal regions of alpha-synuclein. Biochemistry $\underline{41}, 13782-13790$

Kojika M, Sato N, Yaegashi Y, Suzuki Y, Suzuki K, Nakae H (2006): Endotoxin adsorption therapy for septic shock using polymyxin B-immobilized fibres (PMX): evaluation by high-sesitivity endotoxin assay and measurement of the cytokine production capacity. Ther Apher Dial $\underline{10}, 12-18$ 
Kreutzberg G (1996): Microglia: a sensor for pathological events in the CNS. Trends Neurosci $\underline{19}$, 312-318

Kruger R, Kuhn W, Muller T, Woitalla D, Graeber M, Kosel S (1998): Ala30Pro mutation in the gene encoding alpha-synuclein in Parkinson's disease. Nat Genet $\underline{18}, 106-108$

Lalonde R, Bensoula A, Filali M (1995): Rotorod sensorimotor learning in cerebellar mutant mice. Neurosci Res 22(4), 423-426

Lang A, Lozano A (1998): Parkinson's disease. Second of two parts. New Eng J $\underline{339}, 1130-1143$

Langston J, Ballard P, Tetrud J, Reeves A, Kaplan J, Karluk D (1983): Chronic Parkinsonism in humans due to a product of meperidine-analog synthesis. Science $\underline{219}, 979-980$

Laye S, Parnet P, Goujon E, Dantzer R (1994): Peripheral administration of lipopolysaccacharide induces the expression of cytokine transcript in the brain an pituitary of mice Brain. Res Mol Brain Res $\underline{27}, 158-162$

Lee H, Choi C, Lee S (2002): Membrane-bound alpha-synuclein has a high aggregation propensity and the ability to seed the aggregation of the cytosolic form. J Biol Chem 277, 5411-5417

Lemstra A, Groen i'nt Woud J, Hoozemans J, van Haastert E, Rozemüller A, Eikelenboom P (2007): Microglia activation in sepsis: a case-control study. J Neuroinflammation $\underline{4}, 4$

Lewy F: Paralysis agitans; in: Handbuch der Neurologie, Band I: Pathologische Anatomie, hrsg. Lewandowsky M; Springer Verlag, Berlin 1912, 920-933

Li J, Fink A (2001): Effect of familial PD point mutations A30P and A53T on the structural properties, aggregation and fibrillatoin of human alpha-synuclein. Biochemistry 므, 11604-11613 
Lotz M, Ebert S, Esselmann H, Wiltfang J, Gerber J, Nau R (2005): Amyloid beta peptide 1-40 enhances the action of Toll-like receptor-2 and -4 agonists but antagonizes Toll-like receptor-9-induced inflammation in primary mouse microglial cell cultures. J Neurochem $\underline{94}, 289-298$

Lowry O, Rosebrough N, Farr A, Randall R (1951): Protein measurement with the Folin phenol reagent. J Biol Chem 193, 265-275

Lu J, Li L, Tay S, Moochhala S, He B (2007): The function of microglia, either neuroprotection or neurotoxicity, is determined by the equilibrium among factors released from activated microglia in vitro. Brain Res $\underline{1159}$, 8-17

Manyam B (1990): Paralysis agitans and levodopa in "Ayurveda": ancient Indian medical treatise. Mov Disord $\underline{5}, 47-48$

McGeer P, McGeer E (2004): Inflammation and neurodegeneration in Parkinson's disease. Parkinsonism Relat Disord 10, 3-7

McGeer P, Itagaki S, Boyes B, McGeer E (1988): Reactive microglia are positive for HLA-DR in the substantia nigra of Parkinson's and Alzheimer's disease brain. Neurology $\underline{38}, 1285-1291$

Mollenhauer B, Cullen V, Kahn I, Bryan K, Outeiro TF, Pepivani I (2008): Direct quantification of CSF alpha-synuclein by ELISA and first cross-sectional stdy in patiens with neurodegeneration. Exp. Neurol. 213, 315-325

Murray A, Levkoff S, Wetle T, Becket L, Cleary P, Schor J (1993): Acute delirium and funktinal decline in the hospitalized elderly patient. J Gerontol $\underline{48}$, 181-186

Nakajo, S., Shioda, S., Nakai, Y., \& Nakya, K. (1994). Localization of phosphoneuroprotein 14 (PNP14) and its mRNA expression in rat brain determined by immunocytochemitry and in situ hybridisation. Brain Res Mol Brain Res 27, 81-86. 
Nau R, Eiffert H (2002): Modulation of release of proinflammatory bacterial compounds by antibacterials: potential impact on course of inflammation and outcome in sepsis and meningitis. Clin. Microbiol. Rev. 15(1), 95-110

Nguyen M, Julien J, Rivest S (2002): Innate immunity: the missing link in neuroprotection and neurodegeneration? Nat Rev Neurosci $\underline{3}$, 216-227

Nguyen M, D'Aigle T, Gowing G, Julien J, Rivest S (2004): Exacerbation of motor neuron disease by chronic stimulation of innate immunity in a mouse model of amyotrophic lateral sclerosis. J Neurosci 24, 1340-1349

Nicklas R (1984): A quantitative comparison of cellular motile systems. Cell Motil $\underline{4(1)}, 1-5$

Nishioka K, Hayashi S, Farrer M, Singleton A, Yoshino H, Imai H (2006): Clinical heterogeneity of alpha-synuclein gene duplication in Parkinson's disease. Ann Neurol $\underline{59}$, 298-309

O'Neil MJ: The Merck Index: An Encyclopedia of Chemicals, Drugs and Biologicals; 14. Auflage; Merck 2006, New York

Pitossi F, del Rey A, Kabiersch A, Besedovsky H (1997): Induction of cytokine transcripts in the central nervous system and pituitary following peripheral administration of endotoxin to mice. J Neurosci Res $\underline{48}, 287-298$

Polymeropoulus ML, Leroy E, Ide S, Dehejia A, Dutra A, Pike B (1997): Mutation in the alpha-synuclein gene identified in families with Parkinson's disease. Science $\underline{276}, 2045-2047$

Ramsay R, Salach J, Singer T (1986): Uptake of the neurotoxin 1-methyl-4phenylpyridine (MPP+) by mitochondria and its relation to the inhibition of the mitochondrial oxidation of NAD+-linked substrates by MPP+. Biochem Biophys Res Commun 134(2), 743-748

Recchia A, Debetto P, Negro A, Guidolin D, Skaper S, Giusti P (2004): alphaSynuclein and Parkinson's disease. FASEB J $\underline{18}$, 617-626 
Shibayama-Imazu T, Okahashi I, Omata K, Nakajo S, Ochiai H, Nakai Y (1993): Cell and tissue distribution and developmental change of neuron specific 14 kDa protein (phosphoneuroprotein 14). Brain Res $\underline{622}, 17-25$

Sian J, Dexter D, Lees A, Daniel S, Jenner P, Marsden C (1994): Glutathionerelated enzymes in brain in Parkinson's disease. Ann Neurol 36(3), 356-361

Singleton A, Farrer M, Johnson J, Singleton A, Hague S, Kachergus J (2003): Alpha-synuclein locus triplication causes Parkinson's disease. Science $\underline{302}, 841$

Spillantini M, Schmidt M, Lee V, Trojanowski J, Jakes R, Goedert M (1997): Alpha-synuclein in Lewy bodies. Nature $\underline{388}, 839-840$

Spillantini M, Cowther R, Jakes R, Hasegawa M, Goedert M (1998): Alphasynuclein in filamentous inclusions of Lewy bodies from Parkinson's disease and dementia with Lewy bodies. Proc Natl Acad Sci 95, 6469-6473

Starr J (2009): Blood-brain barrier permeability in Alzheimer's disease: a casecontrol MRI study. Psychiatry Res $\underline{171}, 232-241$

Tokuda T, Salem S, Allsop D, Mizuno T, Nakagawa M, Qureshi M (2006): Decreased aöpha-synuclein in cerebrospinal fluid of aged individuals and subjects with Parkinson's disease. Biochem Biophys Res Commun $\underline{349}$, 162166

Trepel M: Mittelhirn (Mesencephalon), in Neuroanatomie - Struktur und Funktion; Elsevier GmbH, Urban \& Fischer, München 2008, 149-170

Turner M, Cagnin A, Turkheimer F, Miller C, Shaw C, Brooks D (2004): Evidence of widespread cerebral microglial activation in amyotrophic lateral sclerosis: an [11C](R)-PK11195 positronemission tomography study. Neurobiol Dis $\underline{15}, 601-609$

Uéda K, Fukushima H, Masliah E, Xia Y, Iwai A, Yoshimoto M (1993): Molecular cloning of cDNA encoding an unrecognized component of amyloid in Alzheimer disease. Proc Natl Acad Sci $\underline{90}, 11282-11286$ 
van der Putten H, Wiederhold K, Probst A, Barbieri S, Mistl C, Danner S (2000): Neuropathology in mice expressing human alpha-synuclein. J Neurosci $\underline{20}$, 6021-6029

van Evenbroeck B, Dobbeleir I, De Waele M, De Leenheir E, Lübke U (2004): Extracellular protein deposition correlates with glial activation and oxidative stress in Creutzfeldt-Jakob and Alzheimer's disease. Acta Neuropathol 108, $194-200$

Weinreb P, Zhen W, Poon A, Conway K, Jr LP (1996): NACP, a protein implicated in Alzheimer's disease and learning, is natively unfolded. Biochemestry 35(43), 13709-13715

Wellmer A, Noeske C, Gerber H, Munzel U, Nau R (2000): Spatial memory and learning deficits after experimental pneumonococcal meningitis in mice. Neurosci Lett 296, 137-140

Westrich J: Die Rolle von alpha-Synuclein im MPTP- und 6-OHDA-Modell des Morbus Parkinson. Med. Diss. Marburg 2008

Wood-Kaczmar A, Gandhi S, Wood N (2006): Understanding the molecular causes of Parkinson's disease. Trends Mol Med 12(11), 521-528

Woods A, Ellis R: Laboratory histopathology: a complete reference. Churchill Livingstone, Edinburgh 1994-96

Wyss-Coray T, Mucke L (2002): Inflammation in neurodegenerative disease - a double-edged sword. Neuron $\underline{35}$ 419-432

Zhang W, Wang T, Pei Z, Miller D, Wu X, Block M, (2005): Aggregated alphasynuclein activates microglia: a process leading to disease progression in Parkinson's disease. FASEB J $\underline{19}$, 533-542

Zlokovic B (2005): Neurovascular mechanisms of Alzheimer's neurodegeneration. Trends Neurosci $\underline{28}, 202-208$ 
Anhang - Abkürzungen

\section{Anhang}

\subsection{Abkürzungen}

A

alpha-Synuclein

$A B \quad$ beta-Amyloid

$A_{b} \quad$ beta-Amyloid

AD Alzheimer-Demenz

AG Antigen

AK Antikörper

ALS Amyotrophe Lateralsklerose

AP Alkalische Phosphatase

Aqua (bi) destillata einfach und zweifach destilliertes Wasser

BCA Bicinchonsäure

BSA Bovine Serum Albumin

Bzw. beziehungsweise

${ }^{\circ} \mathrm{C} \quad$ Grad Celsius

C Zenti-

$\mathrm{Ca} \quad$ Calzium

cDNA c-Desoxyribonukleinsäure

CFU Colony forming units

CJD Creutzfeldt-Jakob-Krankheit

CPG Cytosin-Phosphat-Guanosin 
Anhang - Abkürzungen

CSF

zerebrospinale Flüssigkeit, Liquor

$\mathrm{Cu}$

Kupfer

$\mathrm{CuSO}_{4} \quad$ Kupfersulfat

DAB Diaminobenzidin

DNA Desoxyribonukleinsäure

DTT Dithiothreitol

EAE experimentelle autoimmune Enzephalitis

EDTA Ethylendiamintetraacetet

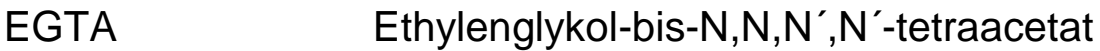

etc. et cetera

FCS Fötales Kälber Serum

GOX Glucoseoxidase

GRKn G-Protein-gekoppelte Rezeptor-kinasen

h

Stunde

HE Hämatoxylin-Eosin

HRP Meerrettichperoxidase (horseraddish peroxidase)

IB4 Isolektin IB4

IgG Immunglobulin $\mathrm{G}$

IPS idiopathischer Morbus Parkinson

I Liter

LB Lewy-Bodies, Lewy-Körperchen

LPS Lipopolysaccharide 
m

$\min$

$\mu$

mol

MOPS

MPP+

MPTP

MS

n

NAC

$\mathrm{NaCl}$

NACP

$\mathrm{NADH}$

$\mathrm{NaOH}$

p

PBS

PCR

PD
Meter, Milli-

Minute

Mikro-

Mol

MOPS/EDTA Buffer, 10X Liquid Concentrate, Prepared with DEPC for RNA applications. 10X concentrate contains 200 mM MOPS, 50 mM EDTA, $21 \mathrm{mM}$ sodium acetate, $\mathrm{pH} 7.0$ at $25^{\circ} \mathrm{C}$.

L-Methyl-Phenyl-Pyridinium-Ion

1-Methyl-4-Phenyl-1,2,3,6-Tetrahydro-Pyridin

Multiple Sklerose

Nano-

Non-Aß-Komponente

Natriumchlorid

Natrium-Cyclopentadienyl

Nicotinamidadenindinukleotid

Natronlauge

Irrtumswahrscheinlichkeit

Phosphat- gepufferte Kochsalzlösung (phosphate buffered

saline)

PBS/0.05\% Tween-20

Polymerase-Ketten-Reaktion

Morbus Parkinson 
Anhang - Abkürzungen

\begin{tabular}{|c|c|}
\hline PIC & Proteaseinhibitorcocktails \\
\hline PMSF & Phenylmethylsulfonylfluorid \\
\hline RT & Raumtemperatur \\
\hline s & Sekunde \\
\hline SDS & Natriumdodecylsulfat \\
\hline SN & Substantia nigra \\
\hline SNpc & Substantia nigra pars compacta \\
\hline S. pneumoniae & Streptococcus pneumoniae \\
\hline $\mathrm{t}$ & Zeit \\
\hline TBS & Tris-buffered saline \\
\hline TEMED & $\mathrm{N}, \mathrm{N}, \mathrm{N}^{\prime}, \mathrm{N}^{\prime}$-Tetramethylethylendiamin \\
\hline TLR-A & Toll-like Rezepter Agonist \\
\hline Tris & Trishydroxylmethylaminomethan \\
\hline vS. & versus \\
\hline WR & Protein-Assay-Working-Reagentz \\
\hline z.B. & zum Beispiel \\
\hline ZNS & zentrales Nervensystem \\
\hline$\%$ & Prozent \\
\hline
\end{tabular}


Abbildungs - und Tabellenverzeichnis

\subsection{Abbildungs- und Tabellenverzeichnis}

\subsubsection{Abbildungsverzeichnis}

ABBILDUNG 1:

ABBILDUNG 2:

ABBILDUNG 3:

ABBILDUNG 4:

ABBILDUNG 5:

ABBILDUNG 6:

ABBILDUNG 7:

ABBILDUNG 8:

ABBILDUNG 9:

ABBILDUNG 10:

ABBILDUNG 11:

ABBILDUNG 12:

ABBILDUNG 13:

ABBILDUNG 14:

ABBILDUNG 15:

ABBILDUNG 16:

ABBILDUNG 17:

ABBILDUNG 18:

\subsubsection{Tabellenverzeichnis}

TABELLE 1:

TABELLE 2:

TABELLE 3:

TABELLE 4

TABELLE 5:

TABELLE 6:

TABELLE 7:

TABELLE 8:

TABELLE 9:

26

TABELLE 10:

TABELLE 11

TABELLE 12

TABELLE 13: 